\title{
Fingolimod for the treatment of neurological diseases - state of play and future perspectives
}

\author{
Robert Brunkhorst ${ }^{1}$, Rajkumar Vutukuri ${ }^{2}$ and Waltraud Pfeilschifter ${ }^{1}$ * \\ ' Cerebrovascular Research Group, Department of Neurology, Frankfurt University Hospital, Frankfurt am Main, Germany \\ 2 Institute of General Pharmacology and Toxicology, pharmazentrum frankfurt, Goethe University Frankfurt, Frankfurt am Main, Germany
}

\section{Edited by:}

Christoph Kleinschnitz, University of

Würzburg, Germany

Reviewed by:

Stine Mencl, University Hospital Würzburg, Germany

Christiane Albert-Weissenberger,

University of Wuerzburg, Germany

*Correspondence:

Waltraud Pfeilschifter

Cerebrovascular Research Group,

Department of Neurology, Frankfurt

University Hospital,

Theodor-Stern-Kai 7, 60590 Frankfurt

am Main, Germany

e-mail: Waltraud.Pfeilschifter@

kgu.de
Sphingolipids are a fascinating class of signaling molecules derived from the membrane lipid sphingomyelin. They show abundant expression in the brain. Complex sphingolipids such as glycosphingolipids (gangliosides and cerebrosides) regulate vesicular transport and lysosomal degradation and their dysregulation can lead to storage diseases with a neurological phenotype. More recently, simple sphingolipids such ceramide, sphingosine and sphingosine 1-phosphate (S1P) were discovered to signal in response to many extracellular stimuli. Forming an intricate signaling network, the balance of these readily interchangeable mediators is decisive for cell fate under stressful conditions. The immunomodulator fingolimod is the prodrug of an S1P receptor agonist. Following receptor activation, the drug leads to downregulation of the $\mathrm{S}_{1} \mathrm{P}_{1}$ receptor inducing functional antagonism. As the first drug to modulate the sphingolipid signaling pathway, it was marketed in 2010 for the treatment of multiple sclerosis (MS). At that time, immunomodulation was widely accepted as the key mechanism of fingolimod's efficacy in MS. But given the excellent passage of this lipophilic compound into the brain and its massive brain accumulation as well as the abundant expression of S1P receptors on brain cells, it is conceivable that fingolimod also affects brain cells directly. Indeed, a seminal study showed that the protective effect of fingolimod in experimental autoimmune encephalitis (EAE), a murine MS model, is lost in mice lacking the $\mathrm{S}_{1} \mathrm{P}_{1}$ receptor on astrocytes, arguing for a specific role of astrocytic S1P signaling in MS. In this review, we discuss the role of sphingolipid mediators and their metabolizing enzymes in neurologic diseases and putative therapeutic strategies arising thereof.

Keywords: sphingosine 1-phosphate, ceramides, sphingosine kinase, sphingosine 1-phosphate receptors, multiple sclerosis, stroke, epilepsy, dementia

\section{THE SPHINGOLIPID SIGNALING PATHWAY}

Sphingolipids have first been described by the German physician Ludwig Thudichum, then living in London (Great Britain) in the end of the 19th century in his book "A treatise on the chemical constitution of the brain". The more complex cerebrosides) are required for cell functions such as cell recogni-

Abbreviations: $\mathrm{AD}$, Alzheimer's disease; $\mathrm{BBB}$, blood-brain barrier; $\mathrm{BDNF}$ brain-derived neurotrophic factor; CNS, central nervous system; EAE, experimental autoimmune encephalitis; ERK1/2, extracellular signal-regulated kinase; GBM, multiform glioblastoma; Gd, gadolinium; HDAC, histone deacetylase; HIF, hypoxia-inducible factor; HP, hypoxic preconditioning; HRE, hypoxia-responsive element; IFN $\gamma$, interferon $\gamma$; IL-1 $\beta$, Interleukin-1 $\beta$; LPP3, lysophospholipid phosphatase 3; LPS, lipopolysaccharide; LTP, longterm potentiation; MRI, magnetic resonance imaging; MS, multiple sclerosis; $\mathrm{PKB} / \mathrm{Akt}$, protein kinase $\mathrm{B} / \mathrm{Akt}$ kinase; RRMS, relapsing-remitting MS; NMDA, N-methyl-D-aspartate; S1P, sphingosine 1-phosphate; $\mathrm{S}_{1} \mathrm{P}_{1-5}, \mathrm{~S} 1 \mathrm{P}$ receptor types 1 to 5; S1PL, sphingosine 1-phosphate lyase; SphK1, sphingosine kinase 1; SphK2, sphingosine kinase 2; SPP, sphingosine 1-phosphate phosphatase; TNF $\alpha$, tumor necrosis factor $\alpha$; t-PA, tissue-type plasminogen activator; TrkB, tropomyosin receptor kinase B; $\operatorname{VEGF} \alpha$, vascular endothelial growth factor $\alpha$. tion, vesicular transport and lysosomal degradation and their dysregulation can lead to storage diseases with a neurological phenotype (Sandhoff and Christomanou, 1979), for example Tay-Sachs disease, Sandhoff disease or Niemann-Pick disease. The physiological relevance of sphingomyelin and its derivatives as signaling molecules gradually came into focus during the last decades, spurred by the discovery of sphingosine as an inhibitor of protein kinase C (Hannun et al., 1986; Wilson et al., 1986, reviewed by Kolesnick, 1991). Numerous reviews focus on the intricate regulation of the sphingolipid pathway (Huwiler et al., 2000; Hannun and Obeid, 2008; Huwiler and Pfeilschifter, 2008) with ceramides and sphingosine 1-phosphate (S1P) functioning as key signaling molecules (Figure 1). The pathway forms a rheostat and the substrates are readily interconvertible. Ceramide, which is derived either from the membrane lipid sphingomyelin by sphingomyelinases or synthesized de novo can be induced by many cell stressors. It acts on defined intracellular targets (reviewed by Huwiler et al., 2000; Ruvolo, 2003) and in general has proinflammatory and proapototic effects. It is degraded to sphingosine, which can be phosphorylated to S1P by sphingosine 


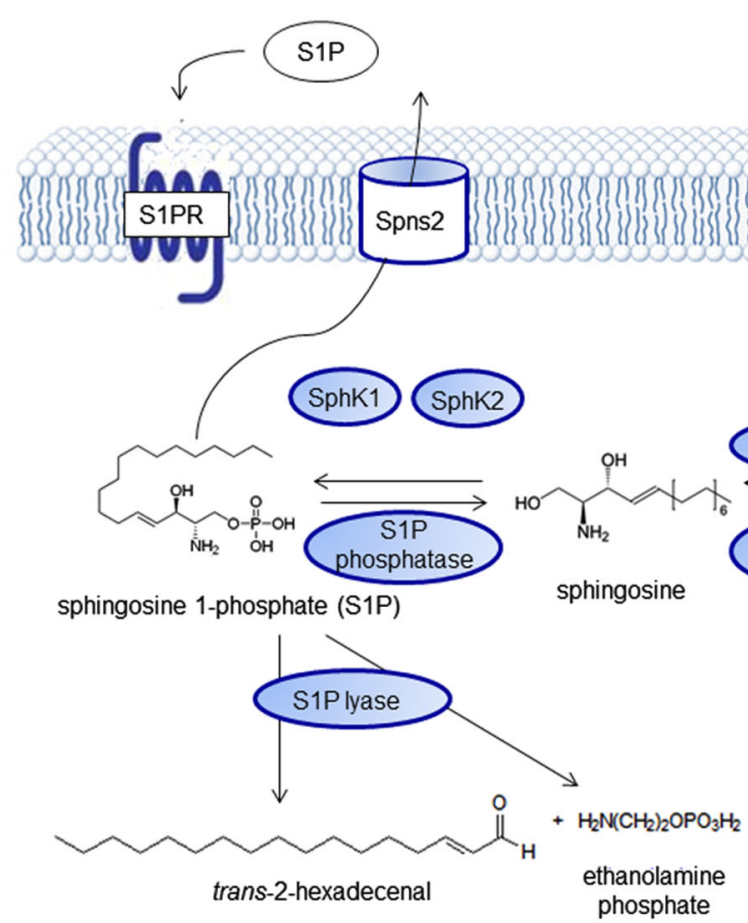

FIGURE 1 | The sphingolipid signaling pathway. Sphingolipid signaling molecules are derived from the membrane lipid sphingomyelin and intricately regulated forming a "rheostat" that can be imbalanced in disease states.

kinase (SphK), an enzyme that exists in two isoforms with different subcellular distribution, SphK1 and SphK2. S1P is an antiinflammtory, proproliferative and antiapoptotic signaling molecule. It was first assumed to act as an intracellular second messenger, because its cellular levels increased upon growth factor stimulation of SphK. However, it took years to identify the first intracellular targets of S1P, whereas it was soon discovered that S1P can signal from the extracellular side through a family of $\mathrm{G}$ protein-coupled receptors (GPCRs), formerly known as Endothelial Differentiation Genes (EDG; Kluk and Hla, 2002). Previously, they had been orphan receptors without known ligands. In 2002, they were renamed by the IUPHAR into

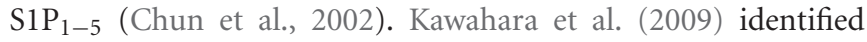
Spinster 2 (Spns2) as a specific outward transporter for S1P (Figure 2).

Mouse models with genetic deletions of S1P receptors and the use of pharmacological tools have been helpful to shed light on the role of S1P in lymphocyte homeostasis, in the development of the cardiovascular and the central nervous system (CNS), and maintenance of endothelial barriers (reviewed by Brinkmann, 2007). $\mathrm{S}_{1} \mathrm{P}_{1-3}$ show a practically ubiquitous expression, whereas $\mathrm{S}_{1} \mathrm{P}_{4}$ expression is mainly detectable on leukocytes but not relevantly in the brain, and $\mathrm{S} \mathrm{P}_{5}$ shows a high expression in oligodendrocytes, the main myelinating cells of the brain. The receptors couple to different $G$ proteins ( $G \alpha i, G \alpha q, G \alpha 12 / 13$ ). From the point-ofview of drug development, the differential receptor expression patterns in different organs, a modulation of receptor expression in disease states, as well as the differential coupling to $G$ proteins, may afford a sufficient degree of specificity to make S1P receptors drugable targets (Figure 2).

Currently, many of the pathophysiologically relevant processes seem to be regulated by the $\mathrm{S}_{1} \mathrm{P}_{1}$ receptor. Studies of S1P receptor knockout mice showed embryonic lethality for $\mathrm{S}_{1} \mathrm{P}_{1}$-deficient mice with defects in vasculogenesis and neural tube formation, supporting the important role of this receptor in developmental processes, but not for mice deficient for one of the other four S1P receptors. The $\mathrm{S}_{1} \mathrm{P}_{1}$ receptor has also been shown to be the relevant receptor to mediate the decisive effect of the vascular S1P gradient on the number of circulating immune cells. S1P concentrations are close to the micromolar range in the bloodstream and concentrations in interstitial fluids are around three orders of magnitude lower. Most prominent are the effects on T lymphocytes: antigen-induced activation of $\mathrm{T}$ cells leads to an up-regulation of $\mathrm{S}_{1} \mathrm{P}_{1}$ and therefore increases the responsiveness to $\mathrm{S} 1 \mathrm{P} . \mathrm{S}_{1} \mathrm{P}_{1}$ regulates $\mathrm{T}$ cell trafficking at multiple stages of $\mathrm{T}$ cell development as well as their responses, e.g., thymocyte egress into the periphery, egress of mature $\mathrm{T}$ cells out of lymph nodes during systemic trafficking and retention of $\mathrm{T}$ cells in non-lymphoid tissues. $\mathrm{B}$ cells do not require $\mathrm{S}_{1} \mathrm{P}_{1}$ to leave the bone marrow but, like $\mathrm{T}$ cells, they need the receptor to exit secondary lymphoid organs (Matloubian et al., 2004; Ledgerwood et al., 2008; Skon et al., 2013). The egress of other immune cells such as eosinophils (Sugita et al., 2010) and natural killer cells (Walzer et al., 2007) also depends on $\mathrm{S} 1 \mathrm{P}$ receptors. In dendritic cells, the functional S1P antagonist fingolimod increased the production of the anti-inflammatory 


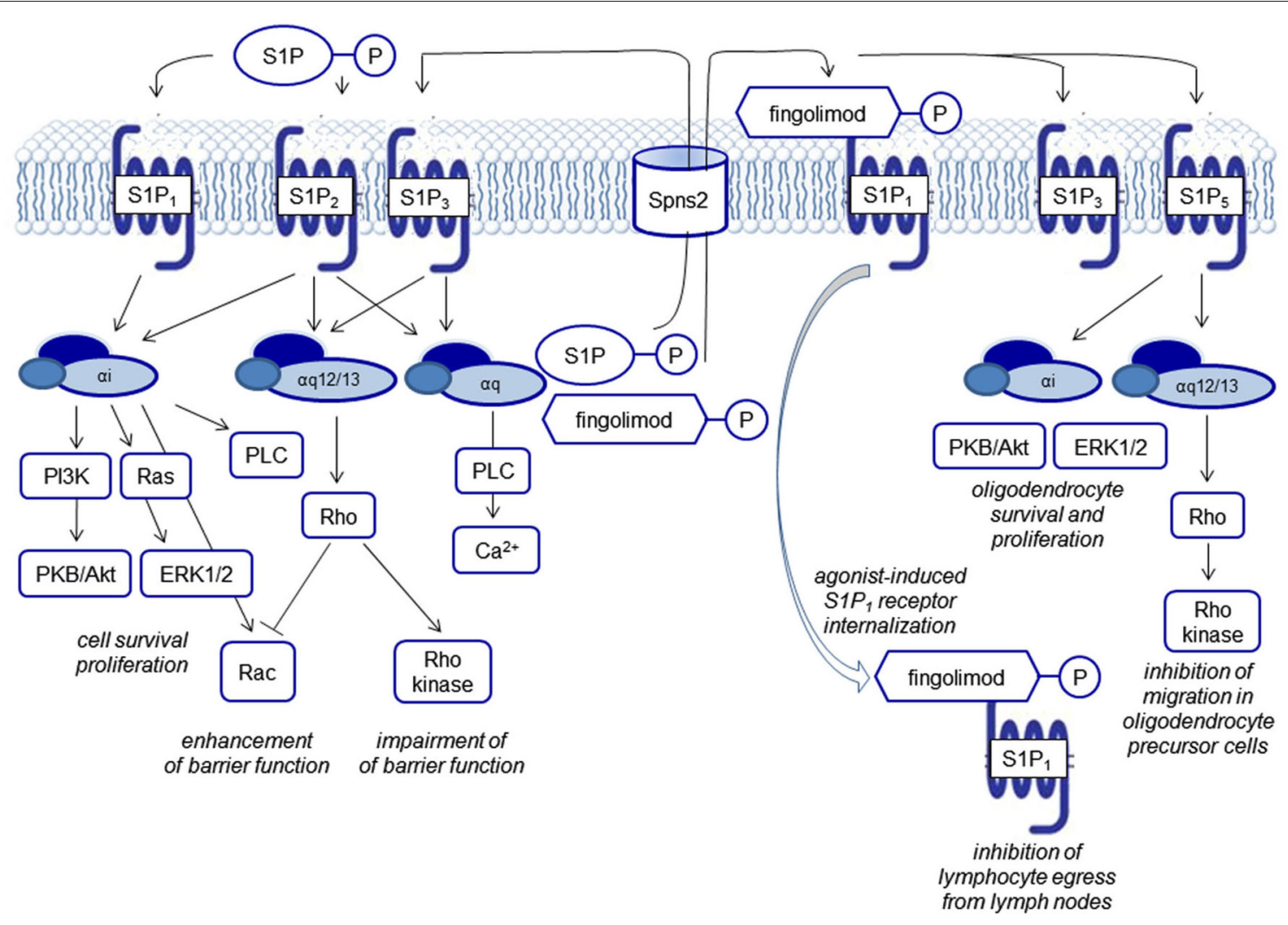

FIGURE 2 | Biological functions of S1P receptor signaling. S1P signals via five $\mathrm{G}$ protein-coupled receptors, termed $\mathrm{S}_{1} \mathrm{P}_{1-5}$. Each of the receptors couples to several G proteins eliciting different downstream events. FTY720 phosphate activates all S1P receptors except S1 $\mathrm{P}_{2}$. S1P and FTY720 phosphate are generated by intracellular phosphorylation of sphingosine and FTY270, respectively and transported outwards to elicit signaling via S1P receptors. Characteristically, FTY720 phosphate leads to agonist-induced receptor internalization of the $\mathrm{S}_{1} \mathrm{P}_{1}$ receptor. cytokine IL-10 and reduced IL-12 secretion (Durafourt et al., 2011).

The vascular S1P gradient also seems to serve as a "tonic" regulator of endothelial barrier integrity. The intricate regulation of barrier function via cytoskeletal rearrangement with opposing functions of the $\mathrm{S} 1 \mathrm{P}$ receptors $\mathrm{S} 1 \mathrm{P}_{1}, \mathrm{~S}_{1} \mathrm{P}_{2}$ and $\mathrm{S} 1 \mathrm{P}_{3}$ signaling via small GTPases of the Rho family and the functional consequences in several disease models have been reviewed by Xiong and Hla (2014; Figure 2).

Besides the S1P receptors, also the SphKs catalyzing S1P formation, SphK1 with cytoplasmic localization and SphK2, the predominant SphK isoform in the brain, with primarily nuclear localization (Igarashi et al., 2003) as well as the S1P degrading enzymes S1P lyase (S1PL; Le Stunff et al., 2002), S1P phosphatases (SPP1 and SPP2), and the lysophospholipid phosphatase 3 (LPP3; Brindley and Pilquil, 2009) have been found to be altered in several neurological diseases and also represent putative targets for drug development (Figure 1).

\section{DISCOVERY AND DEVELOPMENT OF FINGOLIMOD/FTY720}

The substance fingolimod (also known as FTY720) has made a very long and interesting journey from traditional asian medicine to a drug tested in large scale international multicenter randomized-controlled placebo-or standard of care-controlled trials proving its efficacy in the treatment of multiple sclerosis (MS) (reviewed by Im, 2003). It evolved from derivatization of ISP-1 that has been isolated from the fungus Isaria sinclairii. This fungus contributes to the fascinating phenomenon of "vegetable wasps and plant worms", also termed "vegetative wesps" or "winter-insect and summer-plant" according to its Chinese characters, caused by the fungus infecting the living insect host, feeding on it during winter time and growing out of the host insect's cadaver in summer (Fujita et al., 1994). ISP-1 showed 10100 fold greater immunosuppressant activity than ciclosporin A in experimental models (Fujita et al., 1994) and was modified for less gastric toxicity to fingolimod (Kiuchi et al., 2000). In contrast to all known immunosuppressants known at that time, fingolimod acts via a sequestration of circulating mature lymphocytes to the lymph nodes (Chiba et al., 1998) without major alterations of their immune functions such as cytokine secretion (Yanagawa et al., 1998), and thus seemed to promise the prevention of allograft rejection without a severe general immunosuppression (reviewed by Brinkmann et al., 2000). Inspired by the structural similarity of FTY720 to sphingosine (Figure 3) and the fact that $\mathrm{S} 1 \mathrm{P}$ receptors had been identified on lymphocytes, Brinkmann et al. (2002) discovered that fingolimod was phosphorylated by 


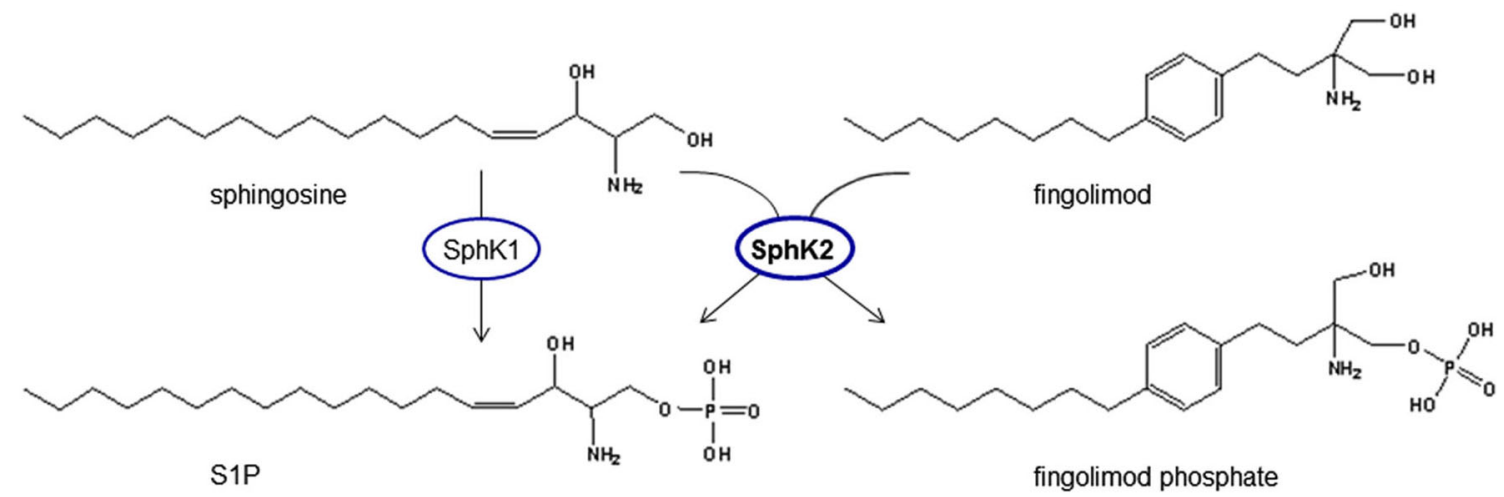

FIGURE 3 | Phosphorylation of fingolimod generates a structural analog to S1P. Fingolimod shows high analogy to sphingosine and is phosphorylated by spingosine kinases, mainly SphK2, which is the predominant SphK isoform in the brain. Fingolimod is a prodrug of fingolimod phosphate that can signal via S1P receptors and activate intracellular targets of S1P.
SphKs to fingolimod phosphate and targeted S1P receptors and thereby could prevent experimental autoimmune encephalitis (EAE), the rodent disease model for MS, in rats. Mandala et al. (2002) provided evidence for lymphocyte sequestration in the lymph nodes secondary to S1P receptor activation. Matloubian et al. (2004) established the $\mathrm{S}_{1} \mathrm{P}_{1}$ receptor to be essential for sensing of the S1P gradient by lymphocytes leading to recirculation and regulation of lymphocyte egress from both thymus and peripheral lymphoid organs. The inhibition of lymphocyte recirculation by fingolimod argues for a functional antagonism of fingolimod phosphate at the $\mathrm{S}_{1} \mathrm{P}_{1}$ receptor. Indeed, Gräler and Goetzl (2004) described a downregulation of S1P receptors upon treatment with fingolimod and Pham et al. (2008) showed in vivo that treatment with fingolimod reduced membrane expression of $\mathrm{S}_{1} \mathrm{P}_{1}$ on lymphocytes. This proposed functional antagonism of fingolimod at $\mathrm{S}_{1} \mathrm{P}_{1}$ is in line with the observation that mutant mice that express an internalization-defective $\mathrm{S}_{1} \mathrm{P}_{1}$ have delayed lymphopenia kinetics in response to fingolimod (Thangada et al., 2010) and that a lymphocytic knock-down of $\mathrm{S}_{1} \mathrm{P}_{1}$ also inhibits their egress from thymus (Allende et al., 2004).

Fingolimod was advanced into large scale randomized controlled trials to prevent allograft rejection in patients with renal transplantations but finally its further development was abandoned because high doses $(2.5 \mathrm{mg} / \mathrm{d}$ and $5 \mathrm{mg} / \mathrm{d})$ did not provide sufficient immunosuppression to allow reduction of coimmunosuppressants and was not superior to standard care. There was an increased incidence of macular edema and transient decreases in heart rate (reviewed by Mansoor and Melendez, 2008). Since 10-100-fold lower doses than those required in animal models of organ graft survival had been highly efficient in EAE (Brinkmann et al., 2010), the focus of clinical development shifted from transplant medicine to MS as an autoimmune disease.

Fingolimod might also have receptor-independent effects on inflammation, especially by binding to intracellular targets of S1P (Hait et al., 2014) or interacting with metabolism and signaling of other lipids. Fingolimod can inhibit both S1P generating as well as degrading enzymes such as SphK1 (Lim et al., 2011), S1PL (Bandhuvula et al., 2005), the ceramide synthases (Lahiri et al., 2009) and the acid sphingomyelinase (ASM; Dawson and Qin, 2011; Figure 4).

Ceramides could also play a role in MS pathophysiology (Qin et al., 2010; Schiffmann et al., 2012) and evidence for an interaction of fingolimod with ceramides has been shown (van Doorn et al., 2012). Fingolimod also appears to inhibit the cannabinoid receptor CB1 (Paugh et al., 2006), which has been shown to have some proinflammatory properties in EAE (Zhang et al., 2009). Additionally, fingolimod can inhibit phospholipase $\mathrm{A}_{2}\left(\mathrm{PLA}_{2}\right)$ activity in mast cells and therefore prostaglandin and thromboxane secretion (Payne et al., 2007). This could contribute to the therapeutic effect of fingolimod in MS, as PLA 2 has been shown to be highly expressed in EAE plaques (Kalyvas and David, 2004) and arachidonic acid is increased in cerebrospinal fluid of MS patients (Dore-Duffy et al., 1991).

\section{CLINICAL EFFICACY OF FINGOLIMOD IN RELAPSING-REMITTING MULTIPLE SCLEROSIS}

MS is an autoimmune disease of the CNS. The primary mechanism is the aberrant formation of autoreactive immune cells directed against CNS antigens. Upon passing the blood-brain barrier (BBB), they meet their antigen and incite inflammatory demyelination leading to subacute neurological symptoms that can remit and, given the chronicity of the disease, relapse. In the early inflammatory phase of the disease, immunomodulation with beta-interferons or glatiramer acetate have been shown to slow disease progression. In later stages of the disease, neurodegenerative processes also play a role.

Fingolimod was approved by the regulatory authorities worldwide as the first oral agent to treat relapsing-remitting multiple sclerosis (RRMS) after the successful completion of two phase III studies in 2010 showed its efficacy. FREEDOMS (Kappos et al., 2010) was a placebo controlled trial and TRANSFORMS (Cohen et al., 2010) even showed the superiority of fingolimod over treatment with intramuscular interferon beta-1a, the standard of care for RRMS. FREEDOMS showed a relative reduction of the 


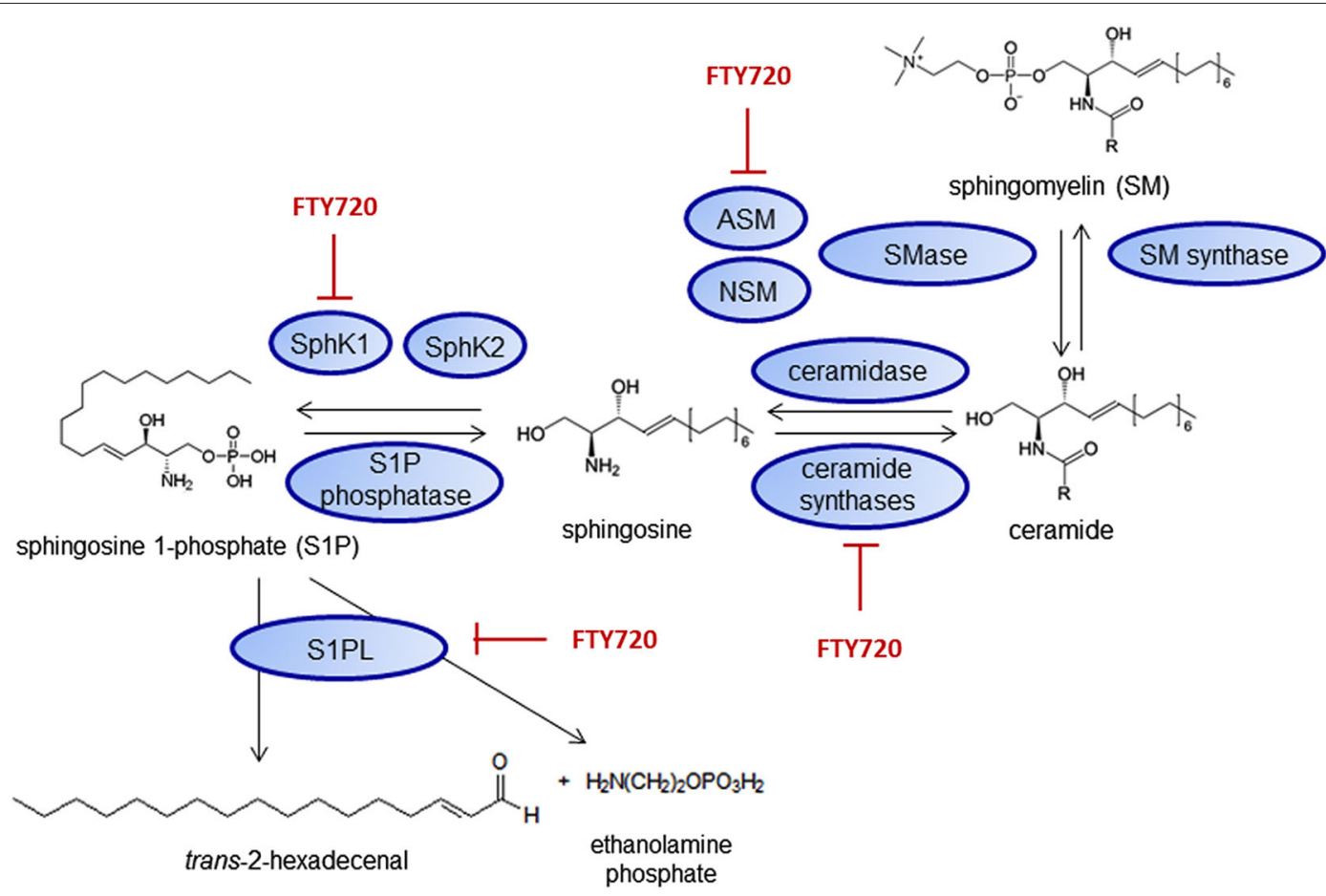

FIGURE 4 | Fingolimod interacts with sphingolipid metabolizing enzymes. Inhibitory effects on SphK1 (Lim et al., 2011), S1PL (Bandhuvula et al., 2005), ceramide synthases (Lahiri et al., 2009) and the acid sphingomyelinase (ASM; Dawson and Qin, 2011) have been shown. NSM—neutral sphingomyelinases.

relapse rate by $54-60 \%$ and a corresponding effect on disability progression (Kappos et al., 2006). TRANSFORMS showed similar relapse rates, although no significant effect on disability. FREEDOMS II, another Phase III placebo controlled trial (Calabresi et al., 2014) initiated by Novartis recently, could reproduce the positive effect of fingolimod on relapse rate. In clinical practice, due to its presumed superiority over interferon beta, fingolimod is one of the first line therapeutic choices for highly active RRMS.

Besides the positive effect on clinical outcome, previous clinical trials (Kappos et al., 2006; Comi et al., 2010) as well as the following phase III studies FREEDOMS, TRANSFORMS and FREEDOMS II have shown effects of fingolimod on magnetic resonance imaging (MRI) outcomes: Gadolinium (Gd) enhanced lesions, the morphological correlates of clinical as well as subclinical relapses, were reduced in the fingolimod treatment group compared to the patients receiving interferon beta- $1 \mathrm{a}$ or placebo. Gd enhancement indicates BBB leakage, which is one of the initial steps in the pathophysiological cascade resulting in a MS plaque. Furthermore, BBB failure is a hallmark of almost every inflammatory reaction in the CNS. Another secondary endpoint of some of the studies cited above was brain atrophy-which was also reduced in fingolimod treated patients. The reduction of Gd-positive lesions demonstrates a direct or indirect antineuroinflammatory effect of fingolimod in patients, whereas the relatively crude parameter brain atrophy might be attributable to a direct neuroprotective mechanism or secondary to a reduced accumulation of MS plaques and secondary neurodegeneration.
As expected from the preceding animal studies, peripheral lymphocyte counts of fingolimod-treated patients are significantly reduced as compared to patients receiving placebo and interferon beta-1a (Cohen et al., 2010; Kappos et al., 2010). In contrast to other cytotoxic immunosuppressive drugs resulting in lymphopenia, the effect of fingolimod on the peripheral circulation of subsets of lymphocytes is reversible (Boulton et al., 2012). In line with the available experimental data, other studies showed that fingolimod selectively inhibits the egress of CCR7positive naive and central memory Tlymphocytes from the lymph node of treated patients (Pham et al., 2008). Effector memory cells represent the largest $\mathrm{T}$ cell population in the blood of patients receiving fingolimod and are important to maintain immune competence (Masopust et al., 2001). Furthermore, these cells did not lose the capacity to produce interferon- $\gamma$ (IFN $\gamma$; Mehling et al., 2008). On the other hand, the CD4+TH17 subset of lymphocytes, which are trapped by fingolimod is believed to have a more pro-inflammatory role in the pathophysiology of MS (Lock et al., 2002; Tzartos et al., 2008). TH17 cells produce proinflammatory IL-17 and IL-22, transmigrate efficiently across the BBB, disrupt tight junctions, highly express neurotoxic substances, and promote CNS inflammation through additional CD4+ T cell and neutrophil recruitment (Kebir et al., 2007). In fingolimod-treated patients, the remaining $\mathrm{CD} 8+\mathrm{T}$ cells are less responsive to the chemokine CCL2 (Johnson et al., 2010) and, therefore, probably less likely recruited to sites of antigen-induced inflammation (Carr et al., 1994). Fingolimod also strongly reduces certain sets of B cell counts in the blood of MS patients (Kowarik et al., 2011). 
The remaining lymphocyte populations appear to be sufficient to protect patients against most infections (Francis et al., 2014). However, there is some evidence for more viral infections, e.g., severe herpes/varizella virus reactivation (Cohen et al., 2010), pointing towards a compromised $\mathrm{T}$ cell function. The broad range of immune regulatory functions of fingolimod seen in patient blood samples and those of experimental animals goes far beyond lymphocyte trafficking and has recently been reviewed by Garris et al. (2014).

In summary, the clinical data on the efficacy of fingolimod in RRMS is robust and has been shown in several independent phase III trials. Additional drugs that modulate S1P signaling are in the pipeline, some of them in advanced clinical trials (reviewed by Bigaud et al., 2014). The dose of $0.5 \mathrm{mg} / \mathrm{d}$ approved for MS treatment, which is decisively lower than doses used in animal models to treat EAE, also leads to peripheral lymphopenia and other immune cell mediated effects in patients. But the MRI findings that fingolimod has unequivocal effects on BBB disruption and brain atrophy suggests additional direct effects of fingolimod in brain cells.

\section{FINGOLIMOD IN EXPERIMENTAL MODELS OF MULTIPLE SCLEROSIS}

Fingolimod was first shown to be effective in EAE in the rat by Brinkmann et al. (2002) at a dose of $0.3 \mathrm{mg} / \mathrm{kg} / \mathrm{d}$. Later studies confirmed these results in different models of MS and different species (Webb et al., 2004; Kataoka et al., 2005). The suppression of EAE in mice and rats by fingolimod correlated with reduced numbers of lymphocytes in the blood and the CNS (Brinkmann et al., 2002; Kataoka et al., 2005).

Besides a prophylactic effect, which is comparable to relapse prevention in patients, a therapeutic effect could also be shown (Kataoka et al., 2005). Even a very late-initiated treatment is able to reverse paralysis (Balatoni et al., 2007), downregulates inflammatory genes such as matrix metalloproteinases and reduces BBB leakiness (Foster et al., 2009). This effect is only one of the mechanisms which appears to be independent of the "classical" role of fingolimod in lymphocyte trafficking. In EAE several additional effects on the immune system have been shown: Fingolimod changes CD8+ effector $\mathrm{T}$ cell function and inhibits their cytotoxic function by inhibition of cytosolic $\mathrm{PLA}_{2}$ and the reduction of IFN $\gamma$ and Granzyme B expression. Interestingly, this effect appears to be independent of S1P receptor modulation as fingolimod phosphate did not elicit these effects (Ntranos et al., 2014). In some EAE-studies, the effect of fingolimod on CNS physiology was analyzed. The observed clinical benefit was accompanied by improvement of electrophysiological abnormalities (Balatoni et al., 2007), demyelination (Papadopoulos et al., 2010) and synaptic dysfunction (Rossi et al., 2012).

At least some of these outcome parameters might be due to an additional effect of fingolimod directly within the CNS. Fingolimod readily penetrates into the CNS and accumulates in the brain and in the spinal cord (Foster et al., 2007). S1P receptors are expressed in cells of the CNS. Interstingly, short-term fingolimod administration can fail to suppress EAE, albeit producing a rapid and substantial reduction of lymphocyte counts (Foster et al.,
2007). Moreover, neurological deficits reappear before lymphocyte numbers normalize if treatment with fingolimod is stopped (Webb et al., 2004). CYM-5442, an S1P $\mathrm{P}_{1}$-selective fingolimod analog that leads to significant levels of the drug in CNS but not in plasma, also improves the disease course in EAE. There was no persisting lymphopenia in these mice but a cyclical recovery from lymphopenia. Nevertheless, $\mathrm{S}_{1} \mathrm{P}_{1}$ expression on neurons and astrocytes was reduced, and levels of cytokines in the CNS were suppressed (Gonzalez-Cabrera et al., 2012).

Furthermore, in alternative MS models, which are based on lymphocyte-independent demyelination, an effect of fingolimod could be observed: Fingolimod enhances remyelination following demyelination of organotypic cerebellar slices (Miron et al., 2010) and in the cuprizone model (Kim et al., 2011), although there is some controversy about the latter model (Hu et al., 2011). Another animal model for MS is the delayed-type hypersensitivity model (DTH) in Lewis rats. Again, an effect of fingolimod could be shown independently of lymphocyte infiltration and $\mathrm{BBB}$ leakage (Anthony et al., 2014).

So what could be the cellular target of fingolimod within the CNS? There is accumulating evidence for a specific role of astrocytes, a cell type which is supposed to play an important role in MS pathophysiology (Brosnan and Raine, 2013). Strong evidence points to an anti-inflammatory effect of fingolimod on astrocytes in vitro (Wu et al., 2013). A particularly illuminating study of Choi et al. (2010) made use of a conditional, cellspecific knock down of the $\mathrm{S}_{1} \mathrm{P}_{1}$ receptor on all cells of the CNS (nestin-cre), neurons (synapsin-cre) and astrocytes (GFAPcre). They found that $\mathrm{S}_{1} \mathrm{P}_{1}$-deficiency on astrocytes led to an attenuation of EAE and that the protective effect of fingolimod in EAE was lost in mice with astrocytic but not with neuronal $\mathrm{S}_{1} \mathrm{P}_{1}$ deletion (Choi et al., 2010). Finally, therapeutic administration of fingolimod to EAE mice has specific effects on astrocyte activation and nitric oxide production (Colombo et al., 2014).

Oligodendrocytes also express S1P receptors, especially the $\mathrm{S} \mathrm{P}_{5}$ receptor, which shows a relatively restricted expression pattern. Interestingly, genetically modified mice with $\mathrm{S}_{1} \mathrm{P}_{5}$ deficiency do not show defects in myelination (Brinkmann, 2007). At least in vitro and in slice cultures direct effects of fingolimod on myelination could be shown (Miron et al., 2008, 2010). A possible role for microglia in the therapeutic effect of fingolimod can be derived from studies of so called microvesicles. They were shown to be significantly reduced in EAE mice treated with fingolimod and are increased in cerebrospinal fluid of MS patients (Verderio et al., 2012). Furthermore, fingolimod treatment leads to a reduced microglial production of pro-inflammatory cytokines such as tumor necrosis factor $\alpha(\mathrm{TNF} \alpha)$, interleukin $1 \beta$ (IL-1 $\beta)$, and interleukin 6 (IL-6; Noda et al., 2013).

An analysis of fingolimod's effects in EAE clearly points towards several contributing mechanisms. Beyond the effect on lymphocyte trafficking, a direct immunmodulatory effect as well as direct effects of fingolimod in the CNS seem to be involved. As new, more receptor-specific agents will enter the scene in the future, it is possible that we will realize that fingolimod as a rather "dirty" drug acting on multiple targets may even prove to be superior to receptor-specific agents. 


\section{STROKE}

Stroke is an acute brain attack caused by the sudden thromboembolic occlusion of a brain vessel with the consequence of cerebral ischemia, the more frequent cause of stroke, or by a rupture of a brain artery causing a hemorrhage into the brain parenchyma. These different stroke entities show the same clinical presentation consisting of a focal neurological deficit such as hemiparesis or aphasia of sudden onset.

\section{CEREBRAL ISCHEMIA}

The embolic blockade of a brain vessel leads to hypoperfusion of the dependent vascular territory in the brain with an almost immediate loss of brain function. However, we know from experimental studies (Astrup et al., 1981) and clinical imaging (Thijs et al., 2002) that the affected brain tissue remains viable for a few hours with the infarct gradually expanding from the core to the periphery of the hypoperfused territory. This is the pathophysiologic correlate of a therapeutic time window for vessel recanalization with thrombolytics or catheter-based interventions. The only approved stroke therapy to date is thrombolysis with recombinant human tissue-type plasminogen activator (t-PA), which is safe and effective within $4.5 \mathrm{~h}$ after symptom onset (Lees et al., 2010). The pathophysiological cascades taking place in the ischemic brain are well characterized and can be roughly summarized by the three interleaving phenomena of excitotoxicity, inflammation and apoptosis (Dirnagl et al., 1999).

In recent years, experimental stroke research has produced strong evidence that cellular immunity and especially $\mathrm{T}$ cells play a decisive role in the fate of brain tissue following cerebral ischemia. Different experimental strategies aiming at a reduction of lymphocyte counts such as the use of genetic models (Hurn et al., 2007; Kleinschnitz et al., 2010); splenectomy prior to stroke (Ajmo et al., 2009), immunosuppressive drugs (Sharkey et al., 1996) or the induction of lymphocytic tolerance (Becker et al., 1997) have shown therapeutic efficacy in experimental stroke models. Therefore, to test the potent immunomodulator fingolimod with its specific lymphocyte-directed immunomodulation in experimental stroke models was a straightforward approach.

Meanwhile, over 10 experimental studies have shown therapeutic efficacy of fingolimod in stroke models in mice and rats (Czech et al., 2009; Shichita et al., 2009; Hasegawa et al., 2010; Pfeilschifter et al., 2011a,b; Wei et al., 2011; Kraft et al., 2013) with doses from 0.25 to $1 \mathrm{mg} / \mathrm{kg}$ applied systemically, leading to a robust lymphocytopenia in rodents (Czech et al., 2009). Reproducible therapeutic effects on lesion size and functional outcome were accompanied by a reduction in pro-apoptotic processes in the infarcted brain areas such as reduced nuclear translocation of apoptosis inducing factor (AIF; Czech et al., 2009), less caspase3 cleavage and TUNEL positive neurons (Hasegawa et al., 2010), and an activation of pro-survival pathways such as extracellular signal-regulated kinase (ERK1/2), protein kinase B/Akt kinase (PKB/Akt) and Bcl-2 upregulation (Hasegawa et al., 2010; Wei et al., 2011). Cell culture experiments did not show relevant neuroprotection by fingolimod in neuronal cells subjected to "ischemia in the dish" stimuli such as glutamate, $\mathrm{H}_{2} \mathrm{O}_{2}$ or hypoxia (Wei et al., 2011; Kraft et al., 2013) but a reduced inflammatory activation of microvascular brain endothelial cells (Wei et al., 2011). Most topical, Kraft et al. (2013) found a reduction of microvascular thromboses in the periinfarct area after fingolimod treatment, a phenomenon that has been observed also previously by the group secondary to several $\mathrm{T}$ cell-directed therapies (Kleinschnitz et al., 2013). Since these findings argue for a role of lymphocytes to boost microvascular thrombus formation in cerebral ischemia, they coined the term thromboinflammation. Of note, there was also one study that reported no therapeutic effect on lesion size and outcome in two different stroke models despite efficient systemic lymphocyte depletion, and decreased cerebral lymphocyte infiltration (Liesz et al., 2011). Similar findings were reported in a recent study on traumatic brain injury (TBI) by Mencl et al. (2014), who assessed the effect of FTY720 in two different experimental models of TBI mimicking focal and diffuse brain injury. FTY720 applied directly prior to the induction of the brain lesion did not reduce lesion size or improve functional neurological outcome neither early or 1 week after the induction of the brain lesion, even though it led to a reduced infiltration of neutrophils and macrophages and/or a reduced microglial activation. TBI, however, is a clearly different entity of brain injury than ischemic stroke. The role of circulating immune cells in lesion development after TBI is less unequivocal and there is most probably not as much microvascular endothelial activation as in ischemic stroke.

Concerning the signaling pathway mediating the protective effect of fingolimod, Hasegawa et al. (2010) demonstrated that this therapeutic effect could also be elicited by the $\mathrm{S}_{1} \mathrm{P}_{1}$-selective agonist SEW2871 and abrogated by the $\mathrm{S}_{1} \mathrm{P}_{1} / \mathrm{S}_{1} \mathrm{P}_{3}$-selective competitive antagonist VPC23019, argueing for an $\mathrm{S}_{1} \mathrm{P}_{1}$-mediated effect. This assumption was supported by findings of Pfeilschifter et al. (2011b) showing that the neuroprotective effect of fingolimod is lost in SphK2 deficient mice, which cannot efficiently phosphorylate and thus activate fingolimod, arguing against a direct effect of non-phosphorylated fingolimod. Hasegawa et al. (2013) examined the expression of the SphK and the S1P $\mathrm{P}_{1}$ receptor in the ischemic area with a focus on neurons $6 \mathrm{~h}$ and $24 \mathrm{~h}$ after stroke by immunohistochemistry, and found a significantly decreased expression of $\mathrm{S}_{1} \mathrm{P}_{1}, \mathrm{SphK}_{1}$, and $\mathrm{SphK}_{2}$ starting at $6 \mathrm{~h}$ and significant at $24 \mathrm{~h}$ after MCAO. Labeling of $\mathrm{S}_{1} \mathrm{P}_{1}$ and both SphKs was reduced in the infarct cortex but remained present in the periinfarct cortex, allowing fingolimod to be phosphorylated and act via inside-out signaling on the $\mathrm{S}_{1} \mathrm{P}_{1}$ receptor.

In analogy to the findings of Choi et al. (2010) in the EAE model, it could be possible that the protective effect of fingolimod only partially depends on the peripheral immunomodulation and also relies on direct effects in the CNS. To weigh the effect of lymphocyte depletion against other putative mechanisms, Kraft et al. (2013) applied fingolimod to recombination activating gene1 (Rag1)-deficient mice that are devoid of T and B lymphocytes. While these mice per se developed smaller infarcts than wild type mice, they were not further protected by fingolimod, showing that the neuroprotective effects of fingolimod largely depends on immunomodulation.

Stroke-associated infections, especially pneumonia, are the most important factor of mortality in the acute phase. They are promoted by a stroke-associated immunodepression 
(Meisel et al., 2005) and will have to be considered prior to any clinical application of fingolimod in the context of stroke. In an experimental stroke model, Pfeilschifter et al. (2011b) did not find an increase of bacterial colonalization in the lungs of fingolimod-treated animals in comparison to control animals $24 \mathrm{~h}$ after stroke. Beyond the acute phase, the fate of stroke survivors is mainly determined by the success of rehabilitative stroke care aiming at functional recovery. Brunkhorst et al. (2013) showed that fingolimod applied from day 3 to day 7 (1 mg/kg b.i.d.) after a photothrombotic lesion directed to the motor cortex of mice relevantly ameliorated functional impairment over an observation period of 31 days, reduced astroglial scarring and increased the size of post-synaptic densities. In this model, fingolimod increased the expression of the trophic factor vascular endothelial growth factor $\alpha(\mathrm{VEGF} \alpha)$ but not of brain-derived neurotrophic factor (BDNF), which has been shown to increase secondary to fingolimod treatment in other models of neurodegenerative diseases.

Another event of importance in the context of stroke, but also intensive care medicine and transplant surgery, which has been shown to be regulated by S1P and fingolimod is preconditioning. Following the principle of "what does not kill you makes you stronger", preconditioning is a process that uses a sublethal noxious stimulus to induce or increase tolerance towards a second noxious stimulus. In stroke research, well established preconditioning stimuli include hypoxic preconditioning (HP), transient ischemia, inhalational anesthetics such as isoflurane or inflammatory agents such as bacterial lipopolysaccharide (LPS). HP is based on a hypoxia-induced stabilization of hypoxiainducible factor (HIF) that is continuously degraded by an oxygen-sensing degradative pathway under normoxic conditions. Stabilized by hypoxia, HIF, which exists in three isoforms, binds to hypoxia-responsive elements (HRE) of hypoxia-regulated genes to promote their transcription. Besides hypoxia and ischemia, also non-hypoxic stimuli such as isoflurane (Sun et al., 2013) or LPS (He et al., 2014) can stabilize HIF. SphK2, but not SphK1 has been shown to be upregulated by HP and isoflurane in the brain (Wacker et al., 2009; Yung et al., 2012) in a HIF-dependent manner (Wacker et al., 2012) and pharmacological inhibition (Wacker et al., 2009) and genetic deletion of SphK2 (Wacker et al., 2012; Yung et al., 2012) were shown to abrogate the protective effects of preconditioning in experimental stroke. There are conflicting findings whether genetic deletion of SphK2, the predominant SphK isoform in the brain (Blondeau et al., 2007) per se exacerbates ischemic damage in stroke or not (Pfeilschifter et al., 2011b; Yung et al., 2012). In other cell systems, HIFmediated upregulation has also been shown for SphK1 (Ader et al., 2008; Schwalm et al., 2008) and both isoforms contain HREs in their respective promotor regions. Wacker et al. (2009, 2012) showed that fingolimod given $48 \mathrm{~h}$ prior to stroke also reduced lesion size and had a strong synergistic effect in conjuction with HP. Therefore, they concluded that fingolimod is a preconditioning agent. While the protective effect after a remote pretreatment $48 \mathrm{~h}$ prior to the insult could be explained by the long-lasting lymphocyte depletion after a single dose of FTY720 (Chiba et al., 1998) and the accumulation of fingolimod in the brain (Foster et al., 2007), the finding that coadministration of R59949, which inhibits HIF accumulation was able to abolish the protective effect of remote fingolimod pretreatment (Wacker et al., 2012) clearly suggests that HIF-mediated gene regulation is downstream of fingolimod. The finding of Yung et al. (2012) that HIF-1 $\alpha$ stabilization following isoflurane preconditioning is lost in SphK2-deficient mice also supports a regulation of HIFmediated signaling by S1P. In synthesis, these findings suggest that in the context of preconditioning and stroke, the signaling between SphK2 and its products fingolimod phosphate or S1P is bidirectional with an induction of SphK2 following preconditioning stimuli and a lost efficacy of HIF-stabilizing factors in SphK2-deficient mice on the one hand and a HIF-dependency of the preconditioning effect of fingolimod on the other hand. The preconditioning effect of HP, the HIF stabilizer cobalt chloride, and of fingolimod was abolished by pretreatment with the $\mathrm{S}_{1} \mathrm{P}_{1}$ specific antagonist W146, supporting an auto- and paracrine propagation of preconditioning by the $\mathrm{S}_{1} \mathrm{P}_{1}$ receptor. Functionally, SphK2 deficiency not only abrogates the neuroprotection by $\mathrm{HP}$ but also $\mathrm{BBB}$ preserving effects of $\mathrm{HP}$ by an alteration in the expression of adhesion molecules in homogenated cortical brain tissue from SphK2-deficient mice analyzed $48 \mathrm{~h}$ after the hypoxic stimulus in comparison to WT mice (Wacker et al., 2012).

\section{THROMBOLYSIS WITH TISSUE PLASMINOGEN ACTIVATOR (t-PA)}

The vascular S1P gradient with high concentrations in the bloodstream and low concentrations in the interstitial fluids is generally viewed as a tonic barrier preserving mechanism for endothelial barriers (reviewed by Xiong and Hla, 2014). Several reports of the efficacy of S1P or fingolimod in experimental states of vascular leakage such as acute lung injury (Peng et al., 2004) or anaphylaxis (Camerer et al., 2009) have sparked interest on a putative therapeutic effect of fingolimod on $\mathrm{BBB}$ disruption after stroke that contributes to potentially fatal brain edema. So far, the data from experimental stroke models on this question are not unequivocal. Cerebral ischemia induces BBB disruption and the thrombolytic t-PA has been shown to aggravate this process (Latour et al., 2004) which accelerates with time from symptom onset, representing the underlying cause of an increased bleeding risk associated with late t-PA treatment, the main obstacle to a more widespread use of this stroke therapy. In a model of moderate size thromboembolic stroke, a faithful model for recanalization by t-PA treatment, fingolimod reduced infarct growth and BBB disruption secondary to late application of t-PA (Campos et al., 2013). By contrast, in a model of large hemispheric strokes and t-PA treatment, fingolimod did not show a beneficial effect (Cai et al., 2013). These contradictory findings can in part be reconciled by the possibility that this massive infarction might have led to an overly rapid loss of SphK and S1P receptors in the infarct and periinfarct region explaining a non-response to fingolimod treatment. Concerning possible future clinical trials of fingolimod in stroke, this would argue against the inclusion of patients with severe stroke symptoms and massive infarctions on brain imaging.

\section{INTRACEREBRAL HEMORRHAGE}

Intracerebral hemorrhage ( $\mathrm{ICH})$ is often denoted as "the most untreatable cause of stroke" because there is no causal treatment 
and it is charged with a high mortality. Noteworthy, Asian populations display higher rates of $\mathrm{ICH}$, with $\mathrm{ICH}$ representing over $30 \%$ of all first ever strokes in China in a meta-analysis of population-based studies (Tsai et al., 2013). Fingolimod has shown therapeutic efficacy in experimental models of $\mathrm{ICH}$ (Rolland et al., 2011, 2013; Lu et al., 2014) with a reduced infiltration of CD3+ lymphocytes and reduced endothelial ICAM-1 expression. Rolland et al. (2013) conducted a 10 week followup of their experimental animals after ICH induction and a single injection or a 3-day course of $1 \mathrm{mg} / \mathrm{kg}$ FTY720 and auspiciously found an improved outcome in neurocognitive scores and brain atrophy with a stronger effect in the animals treated for 3 days. These findings support the observations of a proregenerative effect of FTY720 by Brunkhorst et al. (2013). Lu et al. (2014) described a reduction of apoptotic cell death both in the center and at the edge of the hematoma but no alteration of in the numbers of CD68+ monocytes/macrophages and resident microglia and also reported positive long-term results concerning neurological function and brain atrophy after 2 weeks.

Recently, a first clinical trial was conducted in China, which recruited 23 patients with deep primary $\mathrm{ICH}$. They were randomized to a treatment with placebo or $0.5 \mathrm{mg} / \mathrm{d}$ FTY720 (Gilenya ${ }^{\circledR}$ ) orally for 3 consecutive days (Fu et al., 2014). This very small clinical trial did not detect differences in adverse events such as increased susceptibility to infections. The group reported an improvement of magnetic resonance imaging-based measurements of perihematomal edema volume, but the patient number seems too small to draw valid conclusions about efficacy yet.

\section{NEURODEGENERATIVE DISEASES ALZHEIMER'S DISEASE}

Alzheimer's disease (AD) is the most common age-related neurodegenerative disorder and shows a rising prevalence along with global trends towards increasing life spans. AD leads to a cognitive decline that is attributable to neuronal loss predominantly affecting higher cortical functions (visuospatial orientation, memory, planning and execution of activities, language and arithmetics) whereas cognitive working tempo and drive seem unaltered. Patients are often able to maintain an unremarkable "façade" even in later stages of the disease when brain atrophy, predominantly of the hippocampus and the temporal lobe can be seen in clinical brain imaging. Currently, there is no causal treatment of this devastating disease. While the diseasetriggering mechanisms are yet unknown, the neuropathological hallmarks of $\mathrm{AD}$ consist of the deposition of amyloid- $\beta$ $(\mathrm{A} \beta)$ plaques and the formation of neurofibrillary tangles consisting of hyperphosphorylated tau protein (Braak and Braak, 1991, 1995). Following an ascending course from the entorhinal region to the neocortex, these changes are accompanied by a loss of cortical synapses, which correlates with cognitive decline (DeKosky and Scheff, 1990). Inflammatory processes such as activation of microglia and astrocytes as well as production of inflammatory cytokines occur within and around amyloid plaques (Lukiw and Bazan, 2006). Recently, autopsy studies on brains of $\mathrm{AD}$ patients but also data from experimental dis- ease models of $\mathrm{AD}$ have provided evidence that alterations of the sphingolipid linked to the pathological mechanisms of $\mathrm{AD}$ and that S1P receptor modulation by fingolimod represents a promising therapeutic approach reducing both the production (Takasugi et al., 2013) and the neurotoxicity (Asle-Rousta et al., 2013; Doi et al., 2013; Hemmati et al., 2013; Fukumoto et al., 2014) of $A \beta$ peptide. $A \beta$ is produced from $A \beta$ precursor protein (APP) in the amyloidogenic pathway through sequential cleavage by two aspartate proteases, $\beta$ - and $\gamma$-secretases (Zheng and Koo, 2011). Several studies have implicated cholesterol and sphingolipid-rich membrane microdomains, termed lipid rafts, in the amyloidogenic processing of APP, and the activities of the secretases are influenced by the composition of these lipid rafts (Kalvodova et al., 2005; Osenkowski et al., 2008; Holmes et al., 2012).

There is ample evidence that the sphingolipid metabolism is altered in $\mathrm{AD}$ brains, leading to an accumulation of proapoptotic and proinflammatory ceramides (Han et al., 2001). The expression of the ceramide-generating acid and neutral sphingomyelinases (NSM) has been shown to be upregulated in brains of patients suffering from AD (Filippov et al., 2012) and elevated ceramide levels are linked to an inhibition of glycolysis (Arboleda et al., 2007) and the induction of nitric oxide synthase and oxidative stress (Cutler et al., 2004). Cutler et al. showed elevations of cholesterol levels and ceramide species (especially C18 and C24) that gradually increased in correlation to disease severity in brain samples from $\mathrm{AD}$ patients and over time in a murine model of AD. The accumulation of ceramide species or cholesterol in cultured hippocampal neurons could be reversed by antioxidative treatment with $\alpha$-tocopherol. Mechanistically, this may be attributed to an activation of the neutral sphingomyelinase by $A \beta$, as Jana and Pahan (2010) had shown previously that $\mathrm{A} \beta$ induces neutral sphingomyelinase in an NADPH-dependent pathway leading to ceramide accumulation that has a propapototic effect on cultured neurons. Elevated ceramide levels stabilize the A $\beta$-cleaving enzyme BACE-1 (Puglielli et al., 2003) whereas a reduction of ceramide levels in turn leads to a reduced secretion of APP and A $\beta$ in human neuroblastoma cells (Tamboli et al., 2005), indicating a vicious cycle involving $A \beta$ production, cellular stress and ceramide accumulation. The clinical significance of increased ceramide levels in the pathophysiology of $\mathrm{AD}$ is supported by studies on patient serum and CSF samples that indentified ceramide species as potential biomarkers of $\mathrm{AD}$ (Mielke et al., 2014) and HIV-associated dementia (Bandaru et al., 2007).

Less is known about the role of S1P, the functional opponent of ceramide, in the development of AD. An analysis of post-mortem brain tissues of 9 individuals with a clinical and histopathological diagnosis of $\mathrm{AD}$ and 6 age-matched control individuals by He et al. (2010) revealed a pattern of elevated ASM and acid ceramidase $(\mathrm{AC})$ expression in $\mathrm{AD}$, along with a reduction in sphingomyelin and elevation of ceramide. Sphingosine levels were higher in the AD brains, but levels of the downstream lipid mediator S1P were reduced. This finding was corroborated by a very recent study of Couttas et al. (2014) reporting on sphingosine/S1P levels and SphK activity in post-mortem brain samples from 34 individuals. Not all of the patients had received a clinical diagnosis 
of $\mathrm{AD}$ and the cohort was composed of carriers of the protective apolipoprotein (APO) $\varepsilon 2$ genotype as well as the risk-bearing $\mathrm{APO} \& 4$ genotype. In this cohort, the S1P to sphingosine ratio was higher in hippocampal regions of Apo $\varepsilon 2$ carriers and S1P levels declined in a regiospecific manner most strongly in brain regions with the most advanced histopathological changes. The activity of SphK1 and SphK2, which generate S1P from sphingosine, also decreased with higher histopathological disease scores. Besides a loss of SphK activity, lower S1P levels in AD patients could also be explained by increased activities of the S1P degrading enzymes S1PL and S1PP. Indeed, S1PP1 has been shown to be markedly up-regulated in AD brains using microarray technology (Katsel et al., 2007).

Seemingly in contrast to these findings, Takasugi et al. (2011) described that the activity of $\beta$-site APP cleaving enzyme- 1 (BACE1), the major $\beta$ secretase and rate-limiting enzyme for amyloid- $\beta$ peptide $(A \beta)$ production, is positively modulated by $\mathrm{S} 1 \mathrm{P}$ in mouse neurons. They found that $\beta$-cleavage of APP was inhibited by genetic knockdown of the S1P-generating SphKs in cultured neuronal cells, an effect that was more pronounced when SphK2 was targeted, or by pharmacological inhibition with the SphK-selective inhibitor SKII. Congruently, increasing S1P levels via inhibition of S1PL or the S1PP1 enhanced A $\beta$ secretion. Modifications of extracellular levels of the poorly permeating lipid mediator S1P failed to modulate BACE1 activity and BACE1 was specifically pulled down to matrices carrying S1P. Therefore Takasugi et al. (2011) concluded that the S1P-BACE1 interaction was of a direct intracellular nature and not mediated via membranebound S1P receptors. Translating these findings into a mouse model of $\mathrm{AD}$, they found a protective effect of the SphK inhibitor SKII against $A \beta$ secretion. Since SphK2 is the predominant isoform of the two S1P synthesizing enzymes in the brain (Blondeau et al., 2007) they analyzed SphK2 expression levels and activity in brain specimens from $\mathrm{AD}$ patients in comparison to nondemented individuals. While the overall SphK2 protein levels were decreased in the brains of individuals suffering from dementia, which was explained by progressive neuronal loss and the predominantly neuronal expression of SphK2 in the brain (Blondeau et al., 2007) the relative in vitro activitiy of SphK2 normalized to SphK2 protein levels was significantly increased in AD brains (Takasugi et al., 2011). Due to the normalization of total SphK2 protein levels, these findings do not necessarily stand in contrast to the above-mentioned observations of Couttas et al. (2014) who found a decreased SphK activity of both isoenzymes in postmortem brain specimens from individuals with histopathological features of AD.

A very recent report from Karaca et al. (2014) on the influence of S1P levels in models of S1PL deficiency on APP metabolism sustained detrimental effects of elevated intracellular S1P levels concerning $A \beta$ accumulation. This group found that inhibition of SphK2 reduced the accumulation of amyloidogenic Cterminal fragments of APP whereas genetic deletion of S1PL or downregulation by siRNA, which both were effective in raising intracellular S1P levels, increased their accumulation. This effect could be mimicked by extracellular addition of the easily cellpermeating sphingosine but not by extracellular addition of the polar mediator S1P. Karaca et al. found that the processing of
APP C-terminal fragments to $A \beta 1-40$ and $A \beta 1-42$ was reduced due to an impaired $\gamma$-secretase activity in S1PL-deficient cells and APP C-terminal fragments accumulated in the lysosomal compartments, along with a deregulated expression of other lysosomal proteins and an impairment of the final stage of autophagy. Interestingly, these pathophysiological processes could be alleviated by a mobilization of intracellular calcium from the endoplasmic reticulum, a process that has been shown to be impaired in a model for the lysosomal storage disease Nieman Pick type C (Lloyd-Evans et al., 2008).

Concerning a putative therapeutic effect of fingolimod on $\mathrm{AD}$ progression in experimental models of established disease, there are several reports presenting promising evidence. In a model of intrahippocampal injection of $\mathrm{A} \beta 1-42$ in rats, a 2 week course of fingolimod treatment ( $1 \mathrm{mg} / \mathrm{kg}$ daily i.p.) ameliorated spatial learning and memory in the Morris water maze test at the end of the 2 week course and reduced neuronal damage and caspase3 activation in the hippocampus (Asle-Rousta et al., 2013). Of note, fingolimod did not enhance learning and memory in control animals who received saline injections into the hippocampus. Fingolimod showed equal efficacy as the NMDA receptor antagonist memantine, an approved drug to treat $\mathrm{AD}$ symptoms in the same disease model (Hemmati et al., 2013) and both were able to partly reverse changes of the gene expression pattern induced by $A \beta$ injection. So far, the mechanism underlying these therapeutic effects is not yet clear. It is possible that the systemic immunomodulation dampens the inflammatory reaction to $A \beta$ deposition. Specifically, fingolimod may interfere with the migration of phagocytes in the brain since it has been shown to reduce $\mathrm{A} \beta$-triggered whole blood cell migration along an $\mathrm{A} \beta$ gradient in a Boyden chamber assay in a dose-dependent manner (Kaneider et al., 2004).

Takasugi et al. (2013) analyzed the effects of fingolimod and the $\mathrm{S}_{1} \mathrm{P}_{1}$-specific receptor agonist $\mathrm{KRP} 203$ on $\mathrm{A} \beta$ production in cultured neuronal cells and brain $A \beta$ levels in a murine $A D$ model (Takasugi et al., 2013). In cell culture, they found a dosedependent reduction of $\mathrm{A} \beta$ production by both compounds. Contrary to S1P, fingolimod and KRP203 affected the activity of $\gamma$-but not $\beta$-secretases. Phosphorylation of both compounds by $\mathrm{SphK} 2$ was a prerequisite for their activity as demonstrated by pharmacological inhibition and genetic knockdown of this enzyme. The effects of fingolimod and KRP203 seem to be receptor-independent since $\mathrm{A} \beta$ production was not affected by the $\mathrm{S}_{1} \mathrm{P}_{1}$ agonist $\mathrm{SEW} 2871$ or the $\mathrm{S}_{1} \mathrm{P}_{1}$ antagonist W123, and neither W123 nor the Gai protein inhibitor suramin altered the inhibition of $A \beta$ production by fingolimod. These findings point towards intracellular effects of fingolimod requiring prior phosphorylation by SphK2, and this hypothesis was further corroborated by the finding that extracellular addition of the polar fingolimod phosphate, which poorly permeates cell membranes, also did not effect $\mathrm{A} \beta$ production. Takasugi et al. translated these findings into an animal model of transgenic mice overexpressing human APP and could show opposite effects of a short-course treatment with fingolimod $(0.5 \mathrm{mg} / \mathrm{kg}$ for 6 days $)$ on the production of $A \beta 1-40$ (decreased) and $A \beta 1-42$ (increased), thus showing that fingolimod affects $A \beta$ levels also in vivo (Takasugi et al., 2013). 
Furthermore, direct effects of fingolimod on brain cells have been shown, such as a dose-dependent induction of BDNF production in cultured neurons on mRNA and protein levels that inhibited $\mathrm{A} \beta$-induced neurotoxicity in a dose-dependent fashion (Doi et al., 2013). The trophic effects of BDNF were shown to be mediated via the tropomyosin receptor kinase B ( TrkB) involving the main downstream pathway ERK1/2 phosphorylation. BDNF was also induced by fingolimod in a murine $\mathrm{AD}$ as shown by a BDNF ELISA from mouse brain homogenates (Fukumoto et al., 2014). The translational relevance of these findings is further sustained by the fact that BDNF expression levels are lower in patients with $\mathrm{AD}$.

\section{ANIMAL MODELS OF LEARNING AND MEMORY}

There is increasing evidence that S1P signaling also plays a physiological role in learning processes. S1P has been shown to increase glutamate release from presynaptic terminals in the CA3 pyramidal neurons of the hippocampus in an $\mathrm{S}_{3} \mathrm{P}_{3}$ receptordependent manner (Kanno et al., 2010). S1P induced the translocation of $\mathrm{S}_{1} \mathrm{P}_{3}$ receptors to presynaptic mossy fiber terminals in the CA3 region and long term potentiation depending on the mossy fiber-CA3 pyramidal neuron interaction was inhibited by a SphK inhibitor, an effect that could be reversed by addition of S1P. Again, the positive effect of S1P on long-term potentiation (LTP) could be inhibited by $\mathrm{S}_{3} \mathrm{P}_{3}$ receptor antagonism. SphK1 is highly expressed in mossy fibers of the hippocampus and LTP was significantly impaired in SphK1 knockout mice, showing that SphK1 is required for hippocampal S1P generation. Congruently, mice with genetic deletion of SphK1 showed an impairment of spatial learning and memomory in the Morris water maze. Interestingly, somewhat opposing findings have recently been described by Hait et al. (2014), see below.

Topical work of the last few years has established a role for coagulation factors such as thrombin, plasmin and activated protein $\mathrm{C}(\mathrm{aPC})$ and protease-activated receptors (PAR) in hippocampal learning processes (Maggio et al., 2008; Mannaioni et al., 2008; Yuan et al., 2009). Interestingly, Maggio et al. (2014) characterized aPC as a metaplastic molecule that enhances LTP upon delivery of a subthreshold stimulation. They propose a model in which upon binding to the endothelial protein $\mathrm{C}$ receptor, which is also expressed on astrocytes, aPC activates PAR1, which triggers the SphK-dependent production of S1P. In turn, $\mathrm{S} 1 \mathrm{P}$ binds to the $\mathrm{S}_{1} \mathrm{P}_{1}$ receptor and stimulates intracellular $\mathrm{Ca}^{2+}$ stores, ultimately leading to enhanced LTP.

Very recently, Hait et al. (2014) showed that fingolimod affects learning and memory function by epigenetic regulation of gene expression. After SphK2 dependent phosphorylation, fingolimod phosphate binds to class 1 histone deacetylases (HDAC), some of the few defined targets of intracellular S1P signaling (Hait et al., 2009). Primary hippocampal neurons as well as a neuroblastoma cell line showed a robust, predominantly nuclear expression and activity of SphK2, showing abundant fingolimod phosphorylation within hours of fingolimod treatment. Most of the fingolimod phosphate remained intracellularly, and interfering with SphK2 expression crucially regulated fingolimod phosphate levels. Interestingly, treatment with fingolimod reduced nuclear S1P levels, probably by competition for phosphorylation by SphK2. As shown for S1P in non-neuronal systems (Hait et al., 2009), fingolimod treatment led to histone acetylation, and the negative modulation of this effect by SphK downregulation in a cell membrane-free system of highly purified nuclei as well as the inefficacy of extracellularly-added S1P or fingolimod phosphate showed that this is a purely intracellular inhibitory effect of phosphorylated fingolimod on HDAC activity while the activity of histone acetyltransferases, which have opposing effects, is not influenced by S1P or fingolimod phosphate.

To test the physiological relevance of these observations and following reports on the role of epigenetic regulation, especially histone acetylation in memory and learning processes (Fischer et al., 2010), Hait et al. (2014) chose an experimental model of contextual fear extinction to evaluate the effects of FTY720 on learning and memory in vivo. To exclude well-established complex effects of the immune system on cognitive functions (Kipnis et al., 2004; Brynskikh et al., 2008), T and B cell deficient severe combined immunodeficiency (SCID) mice were used. The contextual fear extinction test evaluates freezing as an expression of acquired fear secondary to an adversive stimulus, and fear extinction upon re-exposure to the same environment without this stimulus and hence is a model for how the individual reduces fear-related reactions to a no longer dangerous stimulus, a mechanism that is impaired in anxiety disorders. Here, fingolimod, which accumulated in the hippocampus, did not change fear acquisition and fear extinction, but alleviated delayed extinction deficits in comparison to saline-treated SCID mice. By contrast, performance in paradigms of tone-dependent fear conditioning that is acquired independently of the hippocampus, exploratory behavior, basal anxiety-like behavior and spatial learning were not influenced by fingolimod treatment in SCID mice. The amelioration of contextual fear extinction in the footshock model was accompanied by increased histone acetylation in the hippocampus and alterations in gene expression of genes linked to synaptic plasticity and learning. In electrophysiological recordings from hippocampal slices, Hait et al. (2014) could show that like other HDAC inhibitors, fingolimod increased LTP as a marker of synaptic plasticity. To confirm the role of SphK2 in hippocampal learning processes and especially SphK2 dependent phosphorylation of fingolimod, they used SphK2 deficient mice, which spontaneously showed impaired visuospatial memory in the Morris water maze and decreased contextual fear extinction. Consistent with the hypothesis that nuclear phosphorylation of fingolimod by SphK2 is a prerequisite of HDAC inhibition, fingolimod failed to rescue fear extinction in this model.

\section{HUNTINGTON DISEASE}

Huntington disease (HD) is an inherited neurodegenerative brain disease with autosomal-dominant inheritance. It is characterized by mutations of the huntingtin gene with extended CAG trinucleotide repeats encoding a dysfunctional mutant huntingtin protein $(\mathrm{mHtt}) . \mathrm{mHtt}$ forms aggregates that are cytotoxic and interfere with many physiological cell functions, such as the expression of neurotrophins, e.g., BDNF (Zuccato et al., 2001). $\mathrm{mHtt}$ accumulation has also been shown to influence lipid metabolism (Maglione et al., 2010) and intraventricular infusion 
of ganglioside GM1 induced phosphorylation and detoxification of mutant huntingtin (Di Pardo et al., 2012). Clinically, this disease which predominantly affects the striatum and the cortex manifests as a hyperkinetic movement disorder with unvoluntary dance-like movements accompanied by a cognitive and psychosocial decline. Symptoms usually begin around the age of 40 and characteristically show an "anticipation" (earlier onset and heavier symptoms from generation to generation) that is linked to an increasing extension of the CAG repeats. Di Pardo et al. (2014) assessed a potential therapeutic effect of fingolimod in transgenic mice expressing exon 1 of the human HD gene carrying a CAG repeat (line R6/2). These mice develop a progressive neurological phenotype with motor symptoms resembling those seen in HD (Carter et al., 1999). Daily fingolimod injections over several weeks, starting in the subtle phase of HD symptoms, significantly ameliorated motor signs of HD and prevented weight loss usually associated with this disease but had no effect on motor tests in WT mice. This was accompanied by activation of the prosurvival pathways of PKB/Akt and ERK1/2 in the striatum. Fingolimodtreated R6/2 mice showed a reduction of brain atrophy and a dramatic reduction of $\mathrm{mHtt}$ aggregates in comparison to untreated mice. Fingolimod was able to partially prevent the reduction in corpus callosum thickness that is observed in R6/2 mice compared to WT mice, a hint towards brain-specific and disease-modifying properties of this drug, which were also supported by increases in DARPP-32, a specific marker of medium spiny neurons and myelin-associated glycoprotein (MAG), a marker of myelin and white matter integrity in R6/2 mice after fingolimod treatment. DiPardo et al. also found a significant increase of cortical BDNF mRNA levels both in R6/2 and WT mice treated with FTY720 and the treatment improved cortical neuronal activity. Interestingly, FTY720-treated mice showed a less pronounced loss of GM1 gangliosides in the striatum, so one putative protective mechanism of FTY720 is preventing the disturbance of the lipid balance.

\section{RETT DISEASE}

Rett disease is a rare congenital neurodegenerative disease with postnatal onset, usually at the age of 6-18 months, linked to a mutation in the MeCP2 gene located on the $\mathrm{x}$ chromosome. Typical for this disease is a relatively normal appearance of infants at birth followed by a developmental regression with severe motor and cognitive deficits. So far, there is no causal treatment. Experiments with MeCP2 -deficient mice have shown an improvement of symptoms by the administration of a small molecule agonist to the neurotrophin receptor TrkB that is activated by BDNF (Schmid et al., 2012). The fact that BDNF levels in MeCP2 mice did not increase in the first weeks after birth as in WT mice (Kolbeck et al., 1999; Chang et al., 2006) as well as a more severe phenotype of $\mathrm{MeCP} 2$ null mice crossed with BDNF-deficient mice or an ameliorated phenotype if MeCP2 null mice were crossed with mice overexpressing BDNF (Chang et al., 2006) pointed towards an influence of BDNF on the course of Rett disease. Furthermore, mice lacking MeCP2 and BDNF in neurons show behavioral similarities (Rauskolb et al., 2010). This makes MeCP2-deficient mice a useful tool to study functional consequences of therapies that raise BDNF levels in the brain. Due to its excellent brain permeability, its confirmed neuroprotective properties in models of cerebral ischemia and the fact that it activates ERK1/2 in neurons-a pathway that is activated by BDNF via the TrkB receptor-prompted Deogracias et al. (2012) to investigate the effects of fingolimod on BDNF levels and disease severity in MeCP2 knockout mice. They found that fingolimod phosphate increased BDNF mRNA and protein in a time- and dose-dependent manner in cultured neuronal cells that were shown to express the $\mathrm{S} 1 \mathrm{P}$ receptors $\mathrm{S}_{1} \mathrm{P}_{1-3}$. The phosphorylation of ERK1/2 and PKB/Akt that occurred in parallel could be shown to be $\mathrm{S}_{1} \mathrm{P}_{1}$ dependent by use of specific agonists and antagonists whereas it was not further clarified whether BDNF induction was an S1P receptor-mediated or direct intracellular effect. In organotypic cortical cultures, Deogracias et al. (2012) showed that addition of fingolimod phosphate increases network activity and by addition of a monoclonal BDNF-blocking antibody could prove that BDNF is in part responsible for this increased activity. This neutralizing BDNF antibody also reversed the antiapoptotic effect of fingolimod phosphate protecting neurons from NMDAinduced death. In vivo, treatment of healthy animals with fingolimod led to increased ERK1/2 phosphorylation and BDNF levels in cortical neurons. In the Rett disease model of MeCP2deficient mice, a 4 week course of fingolimod treatment at a rather low dose $(0.5 \mathrm{mg} / \mathrm{kg}$ every $4 \mathrm{~d})$ lead to increased levels of BDNF in affected brain structures and even to an amelioration of motor impairment and survival. This was the first description of a fingolimod-elicited production of the neurotrophin BDNF which could be attributed primarily to neurons by immunohistochemistry and cell culture experiments while a relevant contribution of astrocytes could be excluded (Deogracias et al., 2012).

\section{EPILEPSY}

Epilepsy is a chronic neurological disorder characterized by repetitive seizures, either of genetic (caused by mutations of genes encoding for excitatory or inhibitory signal tranducers in neurons or glial cells) or structural (caused by a brain lesion such as cerebral infarcts or brain tumors) origin. While epilepsies are well controllable by anticonvulsant medication in the majority of cases, series of recurrent seizures or non-terminating status epilepticus represent a serious threat for patients with epilepsy. The processes happening in the propagation from single seizures to prolonged epileptic activity have been characterized in experimental models and emcompass cell death, axonal and dendritic plasticity, neurogenesis and neuroinflammation (Lukasiuk et al., 2006). Especially neuroinflammatory processes such as glial cell activation and increases in inflammatory cytokines such as IL$1 \beta$ and TNF $\alpha$ have recently gained interest (Ravizza et al., 2011; Vezzani and Friedman, 2011) and the blockade of IL-1 $\beta$ (Maroso et al., 2011) or TNF $\alpha$ (Rao et al., 2008) were shown to effectively decrease seizure activity. Gao et al. (2012) reported a significant decrease in the incidence and duration of spontaneous recurrent seizures by fingolimod treatment in rats that were subjected to an experimental model of lithium/pilocarpine-induced status epilepticus. Rats were treated with fingolimod $1 \mathrm{mg} / \mathrm{kg}$ daily starting $24 \mathrm{~h}$ after the induced status epilepticus and showed a reduced activation of microglia and astrocytes in the hippocampus in comparison to vehicle-treated mice as well as reduced 
hippocampal expression of the proinflammatory cytokines IL-1 $\beta$ and TNF $\alpha$. Concerning a putative effect on neurons, there was abundant staining for the neuronal marker NeuN in immunohistochemical stainings of the hippocampus of healthy rats that was lost to a great degree 4 days after status epilepticus and partially rescued by FTY720 treatment. The loss of NeuN-positive Neurons in the hippocampus was accompanied by mossy fiber sprouting which was also reduced by treatment with FTY720.

Concerning putative non-immunomodulatory effects of FTY720 in epilepsy, it should be noted that mice with a genetic deletion of the $\mathrm{S} \mathrm{P}_{2}$ receptor develop spontaneous, sporadic, and occasionally lethal seizures between 3 and 7 weeks of age (MacLennan et al., 2001). At a cellular level, loss of the $\mathrm{S}_{1} \mathrm{P}_{2}$ receptor leads to a large increase in the excitability of neocortical pyramidal neurons, demonstrating that $\mathrm{S} \mathrm{P}_{2}$ plays an essential and functionally important role in the control of neuronal excitability.

\section{BRAIN TUMORS}

Primary brain tumors most commonly originate from glial cells. Among them, high grade gliomas such as the glioblastoma multiforme (GBM) are the most malignant forms with aggressive growth and invasion of the surrounding brain tissue. Due to their infiltrating nature, they cannot be completely excised and the majority will recur locally (Giese et al., 2004). Life expectancy of patients diagnosed with GBM operated and treated with radiotherapy ranges around 12 months and can be extended by chemotherapy with the DNA alkylating chemotherapeutic temozolomid (TMZ), the current standard of care (Hart et al., 2013). There is increasing evidence that dysregulations of S1P metabolizing enzymes with increased levels of S1P are correlated with malignant properties of GBM. Van Brocklyn et al. (2005) showed that high expression levels of the SphK isoform SphK1 in human astrocytomas correlates with a 3fold shorter median survival of patients whereas in glioblastoma cell lines, RNA interference to knock down SphK2 even had a greater effect on tumor cell proliferation than knock down of SphK1 (Van Brocklyn et al., 2005). Exogenously added S1P has been found to stimulate motility and invasiveness of human GBM cells (Van Brocklyn et al., 2003). GBM cell lines express the S1P receptors $\mathrm{S}_{1} \mathrm{P}_{1}, \mathrm{~S}_{1} \mathrm{P}_{2}$ and $\mathrm{S}_{\mathrm{P}} \mathrm{P}_{3}$. From cellular the lower affinity $\mathrm{S} 1 \mathrm{P}$ receptor ligands dihydro-sphingosine and sphingosylphosphorylcholine in the high nanomolar to low micromolar range, Van Brocklyn et al. (2002) concluded that the proproliferative effects of S1P on astrocytic tumor cell lines are mediated by the S1P1 receptor involving PI3K and ERK1/2 activation rather than by intracellular effects of S1P. This is supported by (partial) abolishments of S1P effects by the Gi protein inhibitor pertussis toxin or the phosphatidylinositol 3-kinase (PI3K) inhibitors wortmannin and LY294002 and the ERK1/2 kinase inhibiting MEK inhibitor U0126.

A thorough analysis of Young and Van Brocklyn (2009) on the contribution of the single $\mathrm{S} 1 \mathrm{P}$ receptors to glioma cell proliferation, migration and invasiveness by means of differential overexpression or RNAi knockdown of the receptors on glioma cell lines established that $\mathrm{S}_{1} \mathrm{P}_{1}, \mathrm{~S}_{1} \mathrm{P}_{2}$ and $\mathrm{S}_{1} \mathrm{P}_{3}$ all contribute positively to S1P-stimulated glioma cell proliferation, with $\mathrm{S}_{1} \mathrm{P}_{1}$ being the major contributor. Stimulation of glioma cell proliferation by these receptors correlated with activation of ERK1/2. Activation of $\mathrm{S} \mathrm{P}_{5}$ inhibited glioma cell proliferation and ERK1/2 activation. $\mathrm{S}_{1} \mathrm{P}_{1}$ and $\mathrm{S}_{1} \mathrm{P}_{3}$ enhance glioma cell migration and invasion. $\mathrm{S}_{2} \mathrm{P}_{2}$ inhibited migration through Rho activation, Rho kinase signaling and stress fiber formation, but enhanced invasiveness of glioma cells by stimulating cell adhesion. Thus, while $\mathrm{S}_{1} \mathrm{P}_{2}$ decreases glioma cell motility, it may enhance tumor cell invasion (Van Brocklyn et al., 2003; Lepley et al., 2005).

This may be in part mediated through induction of proteins that modulate glioma cell interaction with the extracellular matrix. $\mathrm{S}_{1} \mathrm{P}_{2}$ potently enhances expression of CCN1/Cyr61, a matricellular protein which stimulates cellular adhesion, migration, angiogenesis and invasion. A neutralizing antibody to CCN1 blocked $\mathrm{S}_{1} \mathrm{P}_{2}$-stimulated glioma invasion (Van Brocklyn et al., 2003). Expression of CCN1 has been shown to correlate with tumor progression and poor patient prognosis in glioma patients (Xie et al., 2004a) and to enhance tumorigenicity of glioma cells (Xie et al., 2004b). Besides that, uPA and its receptor uPAR, have been established as critical mediators of tumor cell invasiveness (Andreasen et al., 1997). In a subsequent study, Young et al. (2009) found that both CCN1 and uPA are upregulated in a GBM cell line upon treatment with S1P $(100 \mathrm{nM})$. The expression of both proteins was induced through different individual $\mathrm{S} 1 \mathrm{P}$ receptor subtypes that were overexpressed in a GBM cell line that normally expresses very low levels of S1P receptors. $\mathrm{S}_{1} \mathrm{P}_{1}$ and $\mathrm{S}_{1} \mathrm{P}_{2}$ receptors contribute to CCN1 induction while all three receptors, with $\mathrm{S}_{1} \mathrm{P}_{1}$ being the most potent, contribute to induce expression of members of the uPA system. Neutralizing antibodies directed against uPA or CCN1 significantly decreased both basal and S1P-stimulated GBM cell invasiveness. uPA activity and glioma invasion were potently blocked by SphK inhibition. Thus, the SphK/S1P/S1P receptor subtypes have a profound and coordinated effect on expression of several genes which are known to be involved in GBM invasiveness (Young et al., 2009).

Growth factors, including EGF, are known to stimulate SphK1 in several cell types and their overexpression in tumor cells is often associated with worse prognosis (Salomon et al., 1995). Especially the EGF receptor (EGFR) is often overexpressed and mutated in gliomas (Frederick et al., 2000). Estrada-Bernal et al. (2011) showed that treatment of glioma cell lines with EGF led to increases in SphK1 expression and activity. Expression of the constitutively active EGFRvIII mutant in glioma cells mimicked this effect. In addition, siRNA to SphK1 partially inhibited EGFRvIIIinduced growth and survival of glioma cells as well as ERK1/2 activation. Interestingly, this effect could be overridden by treatment with high concentrations $(10 \mu \mathrm{M})$ of S1P but not by lower concentrations. Since $10 \mu \mathrm{M}$ S1P have been shown to activate the intracellular S1P target TRAF2, while lower concentrations of S1P $(10 \mathrm{nM})$ are sufficient to activate the membrane-bound receptors, this hints to receptor-independent intracellular effects (Alvarez et al., 2010). Pharmacological blockade of the EGFR by gefetinib had a rather modest inhibitory effect on glioma cell proliferation whereas pharmacological inhibition of SphK1 strongly blocked proliferation and induced apoptosis of a GBM-derived neurosphere cell line (Estrada-Bernal et al., 2011). These data showed that EGF/EGFR and EGFRvIII signaling induces SphK1 in glioblastoma cells and that SphK1 is necessary to maintain survival of glioblastoma cells. 
A putative therapeutic effect of fingolimod in the context of glioma research was evaluated as early as 2001 (Sonoda et al., 2001), spurred by the finding that higher concentrations of fingolimod in the micromolar range were shown to induce apoptosis in mature T lymphocytes (Enosawa et al., 1996). Sonoda et al. found that fingolimod at rather high concentrations (ED50 between $1-10 \mu \mathrm{g} / \mathrm{ml}$ ) induced apoptosis in the human glioma cell line T89G. FTY720 led to tyrosine dephosphorylation of the focal adhesion kinase (FAK) and inhibited the protective FAK/PI3K pathway leading to an activation of caspase 6. Conversely, the inhibition of protein tyrosine phosphatases by orthovanadate prevented FAK dephosphorylation and inhibited fingolimodinduced cell death. An antitumor effect of fingolimod has been described in many tumor cell types (reviewed by Pitman et al., 2012; Zhang et al., 2013). In most cases, these antitumor effects are caused by unphosphorylated fingolimod, not fingolimod phosphate in cell culture systems and seem to involve direct intracellular effects of fingolimod such as an activation of phosphatase 2A (PP2A), the tumor suppressor PTEN, an inhibition of the PI3K/AKT/mTOR pathway or even an inhibition of SphKs. Estrada-Bernal et al. (2012) reproduced the propapoptotic effect of fingolimod on glioma cells in the pathophysiologically more relevant model of brain tumor stem cells (BTSCs) derived from human GBM tissue. These cells develop neurosphere-like aggregates in cell culture and develop into faithful histological models of human gliomas when injected into the brains of mice. Four different BTSC lines underwent apoptosis at FTY720 concentrations of $1 \mu \mathrm{g} / \mathrm{ml}$ and higher whereas toxicity to non-malignant primary astrocytes began at $10 \mu \mathrm{g} / \mathrm{ml}$ and was thus one order of magnitude higher. Fingolimod led to a rapid dephosphorylation of ERK1/2, upregulation of the $\mathrm{BH} 3$-only protein Bim, and cleavage of caspases 9 and 7 or caspase 3. Fingolimod also reduced BTSC invasiveness and, most importantly, had a synergistic effect in addition to TMZ, the current standard chemotherapeutic agent to treat malignant gliomas, allowing a reduction of the fingolimod dose required for BTSC toxicity. By contrast, fingolimod phosphate was much less effective at inducing apoptosis of BTSC. Generally, in animal models of many cancers, exceedingly high FTY720 doses of $5-10 \mathrm{mg} / \mathrm{kg}$ are required for satisfying effectiveness, as compared to $0.5-1 \mathrm{mg} / \mathrm{kg}$ that were found to be effective in models of cerebral ischemia (Czech et al., 2009; Hasegawa et al., 2010; Wei et al., 2011; Kraft et al., 2013) or neurodegeneration (Deogracias et al., 2012; Takasugi et al., 2013) and even lower doses required in EAE (Brinkmann et al., 2002). This was also described in the experimental glioma model of Estrada-Bernal et al. (2012), who injected glioma BTSCs into nude mice that were treated with either fingolimod $(10 \mathrm{mg} / \mathrm{kg}), \mathrm{TMZ}(5 \mathrm{mg} / \mathrm{kg})$ or a combination of both drugs. This experiment confirmed the efficacy of fingolimod as an experimental glioma therapy that significantly prolonged survival and reduced tumor growth even though it was somewhat less effective than TMZ. The combination of both drugs showed the greatest efficacy. Even if due to yet undefined reasons, the in vivo effect of fingolimod was somewhat weaker than the stunning in vitro effects, fingolimod seems to be a promising (adjuvant) drug to treat gliomas, whose progression is yet barely controlled by the current standard therapies.

\section{SUMMARY AND FUTURE PERSPECTIVES}

According to experimental data, the sphingolipid signaling pathway seems to be of central relevance in the pathophysiology of many diverse neurological diseases. The versatile sphingosine analog fingolimod, prodrug of the S1P-modulating fingolimod phosphate, provides scientifically proven reduction of relapse rate and amelioration of disease progression in MS. But data from experimental animal models suggest that fingolimod has additional therapeutic applications in store. Many of the diseases reviewed here follow a fatal course and treatment options yet are scarce and their efficacy often short-lived. Given the growing body of experience with fingolimod accumulated by clinical neurologists and the favorable safety profile in the indication of MS, there is hope for a translation of some of these experimental findings into the clinics.

\section{ACKNOWLEDGMENTS}

Rajkumar Vutukuri is a stipendiary of the International Research Training Group "Dr. Hans Kröner Graduiertenkolleg” funded by the Else Kröner Fresenius-Stiftung. The publication of this manuscript was supported by a publication grant from NEUROWIND e.V.

\section{REFERENCES}

Ader, I., Brizuela, L., Bouquerel, P., Malavaud, B., and Cuvillier, O. (2008). Sphingosine kinase 1: a new modulator of hypoxia inducible factor lalpha during hypoxia in human cancer cells. Cancer Res. 68, 8635-8642. doi: 10.1158/00085472.CAN-08-0917

Ajmo, C. T., Collier, L. A., Leonardo, C. C., Hall, A. A., Green, S. M., Womble, T. A., et al. (2009). Blockade of adrenoreceptors inhibits the splenic response to stroke. Exp. Neurol. 218, 47-55. doi: 10.1016/j.expneurol.2009.03.044

Allende, M. L., Dreier, J. L., Mandala, S., and Proia, R. L. (2004). Expression of the sphingosine 1-phosphate receptor, S1P1, on T-cells controls thymic emigration. J. Biol. Chem. 279, 15396-15401. doi: 10.1074/jbc.m314291200

Alvarez, S. E., Harikumar, K. B., Hait, N. C., Allegood, J., Strub, G. M., Kim, E. Y., et al. (2010). Sphingosine-1-phosphate is a missing cofactor for the E3 ubiquitin ligase TRAF2. Nature 465, 1084-1088. doi: 10.1038/nature09128

Andreasen, P. A., Kjøller, L., Christensen, L., and Duffy, M. J. (1997). The urokinase-type plasminogen activator system in cancer metastasis: a review. Int. J. Cancer 72, 1-22. doi: 10.1002/(sici)1097-0215(19970703)72:1<1::aid-ijc1>3. $0 . \mathrm{co} ; 2-\mathrm{z}$

Anthony, D. C., Sibson, N. R., Losey, P., Meier, D. P., and Leppert, D. (2014). Investigation of immune and CNS-mediated effects of fingolimod in the focal delayed-type hypersensitivity multiple sclerosis model. Neuropharmacology 79 , 534-541. doi: 10.1016/j.neuropharm.2013.12.022

Arboleda, G., Huang, T.-J., Waters, C., Verkhratsky, A., Fernyhough, P., and Gibson, R. M. (2007). Insulin-like growth factor-1-dependent maintenance of neuronal metabolism through the phosphatidylinositol 3-kinase-Akt pathway is inhibited by C2-ceramide in CAD cells. Eur. J. Neurosci. 25, 3030-3038. doi: 10.1111/j. 1460-9568.2007.05557.x

Asle-Rousta, M., Kolahdooz, Z., Oryan, S., Ahmadiani, A., and Dargahi, L. (2013). FTY720 (fingolimod) attenuates beta-amyloid peptide (A $\beta 42)$-induced impairment of spatial learning and memory in rats. J. Mol. Neurosci. 50, 524-532. doi: 10.1007/s12031-013-9979-6

Astrup, J., Siesjö, B. K., and Symon, L. (1981). Thresholds in cerebral ischemia-the ischemic penumbra. Stroke 12, 723-725. doi: 10.1161/01.str.12.6.723

Balatoni, B., Storch, M. K., Swoboda, E.-M., Schönborn, V., Koziel, A., Lambrou, G. N., et al. (2007). FTY720 sustains and restores neuronal function in the DA rat model of MOG-induced experimental autoimmune encephalomyelitis. Brain Res. Bull. 74, 307-316. doi: 10.1016/j.brainresbull.2007.06.023

Bandaru, V. V. R., McArthur, J. C., Sacktor, N., Cutler, R. G., Knapp, E. L., Mattson, M. P., et al. (2007). Associative and predictive biomarkers of dementia in HIV-1-infected patients. Neurology 68, 1481-1487. doi: 10.1212/01.wnl. 0000260610.79853 .47 
Bandhuvula, P., Tam, Y. Y., Oskouian, B., and Saba, J. D. (2005). The immune modulator FTY720 inhibits sphingosine-1-phosphate lyase activity. J. Biol. Chem. 280, 33697-33700. doi: 10.1074/jbc.c500294200

Becker, K. J., McCarron, R. M., Ruetzler, C., Laban, O., Sternberg, E., Flanders, K. C., et al. (1997). Immunologic tolerance to myelin basic protein decreases stroke size after transient focal cerebral ischemia. Proc. Natl. Acad. Sci. U S A 94, 10873-10878. doi: 10.1073/pnas.94.20.10873

Bigaud, M., Guerini, D., Billich, A., Bassilana, F., and Brinkmann, V. (2014). Second generation S1P pathway modulators: research strategies and clinical developments. Biochim. Biophys. Acta 1841, 745-758. doi: 10.1016/j.bbalip.2013. 11.001

Blondeau, N., Lai, Y., Tyndall, S., Popolo, M., Topalkara, K., Pru, J. K., et al. (2007). Distribution of sphingosine kinase activity and mRNA in rodent brain. J. Neurochem. 103, 509-517. doi: 10.1111/j.1471-4159.2007.04755.x

Boulton, C., Meiser, K., David, O. J., and Schmouder, R. (2012). Pharmacodynamic effects of steady-state fingolimod on antibody response in healthy volunteers: a 4-week, randomized, placebo-controlled, parallel-group, multiple-dose study. J. Clin. Pharmacol. 52, 1879-1890. doi: 10.1177/0091270011427908

Braak, H., and Braak, E. (1991). Demonstration of amyloid deposits and neurofibrillary changes in whole brain sections. Brain Pathol. 1, 213-216. doi: 10.1111/j. 1750-3639.1991.tb00661.x

Braak, H., and Braak, E. (1995). Staging of Alzheimer's disease-related neurofibrillary changes. Neurobiol. Aging 16, 271-278. doi: 10.1016/0197-4580(95) 00021-6

Brindley, D. N., and Pilquil, C. (2009). Lipid phosphate phosphatases and signaling. J. Lipid Res. 50(Suppl), S225-S230. doi: 10.1194/jlr.R800055-JLR200

Brinkmann, V. (2007). Sphingosine 1-phosphate receptors in health and disease: mechanistic insights from gene deletion studies and reverse pharmacology. Pharmacol. Ther. 115, 84-105. doi: 10.1016/j.pharmthera.2007.04.006

Brinkmann, V., Billich, A., Baumruker, T., Heining, P., Schmouder, R., Francis, G., et al. (2010). Fingolimod (FTY720): discovery and development of an oral drug to treat multiple sclerosis. Nat. Rev. Drug Discov. 9, 883-897. doi: 10. $1038 / \operatorname{nrd} 3248$

Brinkmann, V., Davis, M. D., Heise, C. E., Albert, R., Cottens, S., Hof, R., et al. (2002). The immune modulator FTY720 targets sphingosine 1phosphate receptors. J. Biol. Chem. 277, 21453-21457. doi: 10.1074/jbc. c200176200

Brinkmann, V., Pinschewer, D., Chiba, K., and Feng, L. (2000). FTY720: a novel transplantation drug that modulates lymphocyte traffic rather than activation. Trends Pharmacol. Sci. 21, 49-52. doi: 10.1016/s0165-6147(99)01419-4

Brosnan, C. F., and Raine, C. S. (2013). The astrocyte in multiple sclerosis revisited. Glia 61, 453-465. doi: 10.1002/glia.22443

Brunkhorst, R., Kanaan, N., Koch, A., Ferreirós, N., Mirceska, A., Zeiner, P., et al. (2013). FTY720 treatment in the convalescence period improves functional recovery and reduces reactive astrogliosis in photothrombotic stroke. PLoS One 8:e70124. doi: 10.1371/journal.pone.0070124

Brynskikh, A., Warren, T., Zhu, J., and Kipnis, J. (2008). Adaptive immunity affects learning behavior in mice. Brain Behav. Immun. 22, 861-869. doi: 10.1016/j.bbi. 2007.12.008

Cai, A., Schlunk, F., Bohmann, F., Kashefiolasl, S., Brunkhorst, R., Foerch, C., et al. (2013). Coadministration of FTY720 and rt-PA in an experimental model of large hemispheric stroke-no influence on functional outcome and blood-brain barrier disruption. Exp. Transl. Stroke Med. 5:11. doi: 10.1186/2040-7378-5-11

Calabresi, P. A., Radue, E.-W., Goodin, D., Jeffery, D., Rammohan, K. W., Reder, A. T., et al. (2014). Safety and efficacy of fingolimod in patients with relapsing-remitting multiple sclerosis (FREEDOMS II): a double-blind, randomised, placebo-controlled, phase 3 trial. Lancet Neurol. 13, 545-556. doi: 10. 1016/s1474-4422(14)70049-3

Camerer, E., Regard, J. B., Cornelissen, I., Srinivasan, Y., Duong, D. N., Palmer, D., et al. (2009). Sphingosine-1-phosphate in the plasma compartment regulates basal and inflammation-induced vascular leak in mice. J. Clin. Invest. 119, 18711879. doi: $10.1172 /$ jci 38575

Campos, F., Qin, T., Castillo, J., Seo, J. H., Arai, K., Lo, E. H., et al. (2013). Fingolimod reduces hemorrhagic transformation associated with delayed tissue plasminogen activator treatment in a mouse thromboembolic model. Stroke 44, 505-511. doi: 10.1161/STROKEAHA.112.679043

Carr, M. W., Roth, S. J., Luther, E., Rose, S. S., and Springer, T. A. (1994). Monocyte chemoattractant protein 1 acts as a T-lymphocyte chemoattractant. Proc. Natl. Acad. Sci. U S A 91, 3652-3656. doi: 10.1073/pnas.91.9.3652
Carter, R. J., Lione, L. A., Humby, T., Mangiarini, L., Mahal, A., Bates, G. P., et al. (1999). Characterization of progressive motor deficits in mice transgenic for the human Huntington's disease mutation. J. Neurosci. 19, 3248-3257.

Chang, Y.-C., Tzeng, S.-F., Yu, L., Huang, A.-M., Lee, H.-T., Huang, C.-C., et al. (2006). Early-life fluoxetine exposure reduced functional deficits after hypoxicischemia brain injury in rat pups. Neurobiol. Dis. 24, 101-113. doi: 10.1016/j. nbd.2006.06.001

Chiba, K., Yanagawa, Y., Masubuchi, Y., Kataoka, H., Kawaguchi, T., Ohtsuki, M., et al. (1998). FTY720, a novel immunosuppressant, induces sequestration of circulating mature lymphocytes by acceleration of lymphocyte homing in rats. I. FTY720 selectively decreases the number of circulating mature lymphocytes by acceleration of lymphocyte homing. J. Immunol. 160, 5037-5044. doi: 10.1046/j. 1365-2567.1998.00639.x

Choi, J. W., Gardell, S. E., Herr, D. R., Rivera, R., Lee, C. W., Noguchi, K., et al. (2010). FTY720 (fingolimod) efficacy in an animal model of multiple sclerosis requires astrocyte sphingosine 1-phosphate receptor 1 (S1P1) modulation. Proc. Natl. Acad. Sci. U S A 108, 751-756. doi: 10.1073/pnas.1014154108

Chun, J., Goetzl, E. J., Hla, T., Igarashi, Y., Lynch, K. R., Moolenaar, W., et al. (2002). International Union of Pharmacology. XXXIV. Lysophospholipid receptor nomenclature. Pharmacol. Rev. 54, 265-269. doi: 10.1124/pr.54.2.265

Cohen, J. A., Barkhof, F., Comi, G., Hartung, H.-P., Khatri, B. O., Montalban, X., et al. (2010). Oral fingolimod or intramuscular interferon for relapsing multiple sclerosis. N. Engl. J. Med. 362, 402-415. doi: 10.1056/NEJMoa09 07839

Colombo, E., Dario, M. D., Capitolo, E., Chaabane, L., Newcombe, J., Martino, G., et al. (2014). Fingolimod may support neuroprotection via blockade of astrocyte nitric oxide. Ann. Neurol. doi: 10.1002/ana.24217. [Epub ahead of print].

Comi, G., O'Connor, P., Montalban, X., Antel, J., Radue, E.-W., Karlsson, G., et al. (2010). Phase II study of oral fingolimod (FTY720) in multiple sclerosis: 3-year results. Mult. Scler. 16, 197-207. doi: 10.1177/1352458509357065

Couttas, T. A., Kain, N., Daniels, B., Lim, X. Y., Shepherd, C., Kril, J., et al. (2014). Loss of the neuroprotective factor Sphingosine 1-phosphate early in Alzheimer's disease pathogenesis. Acta Neuropathol. Commun. 2:9. doi: 10.1186/20515960-2-9

Cutler, R. G., Kelly, J., Storie, K., Pedersen, W. A., Tammara, A., Hatanpaa, K., et al. (2004). Involvement of oxidative stress-induced abnormalities in ceramide and cholesterol metabolism in brain aging and Alzheimer's disease. Proc. Natl. Acad. Sci. U S A 101, 2070-2075. doi: 10.1073/pnas.0305799101

Czech, B., Pfeilschifter, W., Mazaheri-Omrani, N., Strobel, M. A., Kahles, T., Neumann-Haefelin, T., et al. (2009). The immunomodulatory sphingosine 1phosphate analog FTY720 reduces lesion size and improves neurological outcome in a mouse model of cerebral ischemia. Biochem. Biophys. Res. Commun. 389, 251-256. doi: 10.1016/j.bbrc.2009.08.142

Dawson, G., and Qin, J. (2011). Gilenya (FTY720) inhibits acid sphingomyelinase by a mechanism similar to tricyclic antidepressants. Biochem. Biophys. Res. Commun. 404, 321-323. doi: 10.1016/j.bbrc.2010.11.115

DeKosky, S. T., and Scheff, S. W. (1990). Synapse loss in frontal cortex biopsies in Alzheimer's disease: correlation with cognitive severity. Ann. Neurol. 27, 457464. doi: 10.1002/ana.410270502

Deogracias, R., Yazdani, M., Dekkers, M. P. J., Guy, J., Ionescu, M. C. S., Vogt, K. E., et al. (2012). Fingolimod, a sphingosine-1 phosphate receptor modulator, increases BDNF levels and improves symptoms of a mouse model of Rett syndrome. Proc. Natl. Acad. Sci. U S A 109, 14230-14235. doi: 10.1073/pnas. 1206093109

Di Pardo, A., Amico, E., Favellato, M., Castrataro, R., Fucile, S., Squitieri, F., et al. (2014). FTY720 (fingolimod) is a neuroprotective and disease-modifying agent in cellular and mouse models of Huntington disease. Hum. Mol. Genet. 23, 2251-2265. doi: $10.1093 / \mathrm{hmg} / \mathrm{ddt} 615$

Di Pardo, A., Maglione, V., Alpaugh, M., Horkey, M., Atwal, R. S., Sassone, J., et al. (2012). Ganglioside GM1 induces phosphorylation of mutant huntingtin and restores normal motor behavior in Huntington disease mice. Proc. Natl. Acad. Sci. US A 109, 3528-3533. doi: 10.1073/pnas.1114502109

Dirnagl, U., Iadecola, C., and Moskowitz, M. A. (1999). Pathobiology of ischaemic stroke: an integrated view. Trends Neurosci. 22, 391-397. doi: 10.1016/s01662236(99)01401-0

Doi, Y., Takeuchi, H., Horiuchi, H., Hanyu, T., Kawanokuchi, J., Jin, S., et al. (2013). Fingolimod phosphate attenuates oligomeric amyloid $\beta$-induced neurotoxicity via increased brain-derived neurotrophic factor expression in neurons. PLoS One 8:e61988. doi: 10.1371/journal.pone.0061988 
Dore-Duffy, P., Ho, S. Y., and Donovan, C. (1991). Cerebrospinal fluid eicosanoid levels: endogenous PGD2 and LTC4 synthesis by antigen-presenting cells that migrate to the central nervous system. Neurology 41, 322-324. doi: 10.1212/wnl. 41.2_part_1.322

Durafourt, B. A., Lambert, C., Johnson, T. A., Blain, M., Bar-Or, A., and Antel, J. P. (2011). Differential responses of human microglia and blood-derived myeloid cells to FTY720. J. Neuroimmunol. 230, 10-16. doi: 10.1016/j.jneuroim.2010.08. 006

Enosawa, S., Suzuki, S., Kakefuda, T., Li, X. K., and Amemiya, H. (1996). Induction of selective cell death targeting on mature T-lymphocytes in rats by a novel immunosuppressant, FTY720. Immunopharmacology 34, 171-179. doi: 10. 1016/0162-3109(96)00132-4

Estrada-Bernal, A., Lawler, S. E., Nowicki, M. O., Ray Chaudhury, A., and Van Brocklyn, J. R. (2011). The role of sphingosine kinase-1 in EGFRvIII-regulated growth and survival of glioblastoma cells. J. Neurooncol. 102, 353-366. doi: 10. 1007/s11060-010-0345-Z

Estrada-Bernal, A., Palanichamy, K., Ray Chaudhury, A., and Van Brocklyn, J. R. (2012). Induction of brain tumor stem cell apoptosis by FTY720: a potential therapeutic agent for glioblastoma. Neuro. Oncol. 14, 405-415. doi: 10. 1093/neuonc/nos005

Filippov, V., Song, M. A., Zhang, K., Vinters, H. V., Tung, S., Kirsch, W. M., et al. (2012). Increased ceramide in brains with Alzheimer's and other neurodegenerative diseases. J. Alzheimers Dis. 29, 537-547. doi: 10.3233/JAD2011-111202

Fischer, A., Sananbenesi, F., Mungenast, A., and Tsai, L.-H. (2010). Targeting the correct HDAC(s) to treat cognitive disorders. Trends Pharmacol. Sci. 31, 605617. doi: 10.1016/j.tips.2010.09.003

Foster, C. A., Howard, L. M., Schweitzer, A., Persohn, E., Hiestand, P. C., Balatoni, B., et al. (2007). Brain penetration of the oral immunomodulatory drug FTY720 and its phosphorylation in the central nervous system during experimental autoimmune encephalomyelitis: consequences for mode of action in multiple sclerosis. J. Pharmacol. Exp. Ther. 323, 469-475. doi: 10.1124/jpet.107. 127183

Foster, C. A., Mechtcheriakova, D., Storch, M. K., Balatoni, B., Howard, L. M., Bornancin, F., et al. (2009). FTY720 rescue therapy in the dark agouti rat model of experimental autoimmune encephalomyelitis: expression of central nervous system genes and reversal of blood-brain-barrier damage. Brain Pathol. 19, 254266. doi: 10.1111/j.1750-3639.2008.00182.x

Francis, G., Kappos, L., O’Connor, P., Collins, W., Tang, D., Mercier, F., et al. (2014). Temporal profile of lymphocyte counts and relationship with infections with fingolimod therapy. Mult. Scler. 20, 471-480. doi: 10.1177/135245851 3500551

Frederick, L., Wang, X. Y., Eley, G., and James, C. D. (2000). Diversity and frequency of epidermal growth factor receptor mutations in human glioblastomas. Cancer Res. 60, 1383-1387.

Fu, Y., Hao, J., Zhang, N., Ren, L., Sun, N., Li, Y.-J., et al. (2014). Fingolimod for the treatment of intracerebral hemorrhage: a 2-arm proof-of-concept study. JAMA Neurol. doi: 10.1001/jamaneurol.2014.1065. [Epub ahead of print].

Fujita, T., Inoue, K., Yamamoto, S., Ikumoto, T., Sasaki, S., Toyama, R., et al. (1994). Fungal metabolites. Part 11. A potent immunosuppressive activity found in Isaria sinclairii metabolite. J. Antibiot. (Tokyo) 47, 208-215. doi: 10. 7164/antibiotics.47.208

Fukumoto, K., Mizoguchi, H., Takeuchi, H., Horiuchi, H., Kawanokuchi, J., Jin, S., et al. (2014). Fingolimod increases brain-derived neurotrophic factor levels and ameliorates amyloid $\beta$-induced memory impairment. Behav. Brain Res. 268, 88-93. doi: 10.1016/j.bbr.2014.03.046

Gao, F., Liu, Y., Li, X., Wang, Y., Wei, D., and Jiang, W. (2012). Fingolimod (FTY720) inhibits neuroinflammation and attenuates spontaneous convulsions in lithium-pilocarpine induced status epilepticus in rat model. Pharmacol. Biochem. Behav. 103, 187-196. doi: 10.1016/j.pbb.2012.08.025

Garris, C. S., Blaho, V. A., Hla, T., and Han, M. H. (2014). Sphingosine-1-phosphate receptor 1 signalling in T cells: trafficking and beyond. Immunology 142, 347353. doi: 10.1111/imm.12272

Giese, A., Kucinski, T., Knopp, U., Goldbrunner, R., Hamel, W., Mehdorn, H. M., et al. (2004). Pattern of recurrence following local chemotherapy with biodegradable carmustine (BCNU) implants in patients with glioblastoma. $J$. Neurooncol. 66, 351-360. doi: 10.1023/b:neon.0000014539.90077.db

Gonzalez-Cabrera, P. J., Cahalan, S. M., Nguyen, N., Sarkisyan, G., Leaf, N. B., Cameron, M. D., et al. (2012). S1P(1) receptor modulation with cyclical recovery from lymphopenia ameliorates mouse model of multiple sclerosis. Mol. Pharmacol. 81, 166-174. doi: 10.1124/mol.111.076109

Gräler, M. H., and Goetzl, E. J. (2004). The immunosuppressant FTY720 downregulates sphingosine 1-phosphate G-protein-coupled receptors. FASEB J. 18, 551-553.

Hait, N. C., Allegood, J., Maceyka, M., Strub, G. M., Harikumar, K. B., Singh, S. K., et al. (2009). Regulation of histone acetylation in the nucleus by sphingosine-1phosphate. Science 325, 1254-1257. doi: 10.1126/science.1176709

Hait, N. C., Wise, L. E., Allegood, J. C., O’Brien, M., Avni, D., Reeves, T. M., et al. (2014). Active, phosphorylated fingolimod inhibits histone deacetylases and facilitates fear extinction memory. Nat. Neurosci. 17, 971-980. doi: 10.1038/nn. 3728

Han, X., Holtzman, D. M., and McKeel, D. W. (2001). Plasmalogen deficiency in early Alzheimer's disease subjects and in animal models: molecular characterization using electrospray ionization mass spectrometry. J. Neurochem. 77, 11681180. doi: 10.1046/j.1471-4159.2001.00332.x

Hannun, Y. A., Loomis, C. R., Merrill, A. H., and Bell, R. M. (1986). Sphingosine inhibition of protein kinase $\mathrm{C}$ activity and of phorbol dibutyrate binding in vitro and in human platelets. J. Biol. Chem. 261, 12604-12609.

Hannun, Y. A., and Obeid, L. M. (2008). Principles of bioactive lipid signalling: lessons from sphingolipids. Nat. Rev. Mol. Cell Biol. 9, 139-150. doi: 10. 1038/nrm2329

Hart, M. G., Garside, R., Rogers, G., Stein, K., and Grant, R. (2013). Temozolomide for high grade glioma. Cochrane Database Syst. Rev. 4:CD007415. doi: 10. 1002/14651858.CD007415

Hasegawa, Y., Suzuki, H., Altay, O., Rolland, W., and Zhang, J. H. (2013). Role of the sphingosine metabolism pathway on neurons against experimental cerebral ischemia in rats. Transl. Stroke Res. 4, 524-532. doi: 10.1007/s12975-0130260-7

Hasegawa, Y., Suzuki, H., Sozen, T., Rolland, W., and Zhang, J. H. (2010). Activation of sphingosine 1-phosphate receptor-1 by FTY720 is neuroprotective after ischemic stroke in rats. Stroke 41, 368-374. doi: 10.1161/STROKEAHA.109. 568899

He, K., Chen, X., Han, C., Xu, L., Zhang, J., Zhang, M., et al. (2014). Lipopolysaccharide-induced cross-tolerance against renal ischemia-reperfusion injury is mediated by hypoxia-inducible factor- $2 \alpha$-regulated nitric oxide production. Kidney Int. 85, 276-288. doi: 10.1038/ki.2013.342

He, X., Huang, Y., Li, B., Gong, C.-X., and Schuchman, E. H. (2010). Deregulation of sphingolipid metabolism in Alzheimer's disease. Neurobiol. Aging 31, 398408. doi: 10.1016/j.neurobiolaging.2008.05.010

Hemmati, F., Dargahi, L., Nasoohi, S., Omidbakhsh, R., Mohamed, Z., Chik, Z., et al. (2013). Neurorestorative effect of FTY720 in a rat model of Alzheimer's disease: comparison with memantine. Behav. Brain Res. 252, 415-421. doi: 10. 1016/j.bbr.2013.06.016

Holmes, O., Paturi, S., Ye, W., Wolfe, M. S., and Selkoe, D. J. (2012). Effects of membrane lipids on the activity and processivity of purified $\gamma$-secretase. Biochemistry 51, 3565-3575. doi: 10.1021/bi300303g

Hu, Y., Lee, X., Ji, B., Guckian, K., Apicco, D., Pepinsky, R. B., et al. (2011). Sphingosine 1-phosphate receptor modulator fingolimod (FTY720) does not promote remyelination in vivo. Mol. Cell. Neurosci. 48, 72-81. doi: 10.1016/j. mcn.2011.06.007

Hurn, P. D., Subramanian, S., Parker, S. M., Afentoulis, M. E., Kaler, L. J., Vandenbark, A. A., et al. (2007). T- and B-cell-deficient mice with experimental stroke have reduced lesion size and inflammation. J. Cereb. Blood Flow Metab. 27, 1798-1805. doi: 10.1038/sj.jcbfm.9600482

Huwiler, A., Kolter, T., Pfeilschifter, J., and Sandhoff, K. (2000). Physiology and pathophysiology of sphingolipid metabolism and signaling. Biochim. Biophys. Acta 1485, 63-99. doi: 10.1016/s1388-1981(00)00042-1

Huwiler, A., and Pfeilschifter, J. (2008). New players on the center stage: sphingosine 1-phosphate and its receptors as drug targets. Biochem. Pharmacol. 75, 1893-1900. doi: 10.1016/j.bcp.2007.12.018

Igarashi, N., Okada, T., Hayashi, S., Fujita, T., Jahangeer, S., and Nakamura, S. (2003). Sphingosine kinase 2 is a nuclear protein and inhibits DNA synthesis. J. Biol. Chem. 278, 46832-46839. doi: 10.1074/jbc.m3065 77200

Im, D. S. (2003). Linking Chinese medicine and G-protein-coupled receptors. Trends Pharmacol. Sci. 24, 2-4. doi: 10.1016/s0165-6147(02)00012-3

Jana, A., and Pahan, K. (2010). Fibrillar amyloid-beta-activated human astroglia kill primary human neurons via neutral sphingomyelinase: implications for 
Alzheimer's disease. J. Neurosci. 30, 12676-12689. doi: 10.1523/JNEUROSCI. 1243-10.2010

Johnson, T. A., Lapierre, Y., Bar-Or, A., and Antel, J. P. (2010). Distinct properties of circulating CD8 $+\mathrm{T}$ cells in FTY720-treated patients with multiple sclerosis. Arch. Neurol. 67, 1449-1455. doi: 10.1001/archneurol. 2010.312

Kalvodova, L., Kahya, N., Schwille, P., Ehehalt, R., Verkade, P., Drechsel, D., et al. (2005). Lipids as modulators of proteolytic activity of BACE: involvement of cholesterol, glycosphingolipids and anionic phospholipids in vitro. J. Biol. Chem. 280, 36815-36823. doi: 10.1074/jbc.m504484200

Kalyvas, A., and David, S. (2004). Cytosolic phospholipase A2 plays a key role in the pathogenesis of multiple sclerosis-like disease. Neuron 41, 323-335. doi: 10. 1016/s0896-6273(04)00003-0

Kaneider, N. C., Lindner, J., Feistritzer, C., Sturn, D. H., Mosheimer, B. A., Djanani, A. M., et al. (2004). The immune modulator FTY720 targets sphingosine-kinasedependent migration of human monocytes in response to amyloid beta-protein and its precursor. FASEB J. 18, 1309-1311.

Kanno, T., Nishizaki, T., Proia, R. L., Kajimoto, T., Jahangeer, S., Okada, T., et al. (2010). Regulation of synaptic strength by sphingosine 1-phosphate in the hippocampus. Neuroscience 171, 973-980. doi: 10.1016/j.neuroscience.2010. 10.021

Kappos, L., Antel, J., Comi, G., Montalban, X., O’Connor, P., Polman, C. H., et al. (2006). Oral fingolimod (FTY720) for relapsing multiple sclerosis. N. Engl. J. Med. 355, 1124-1140. doi: 10.1056/NEJMoa052643

Kappos, L., Radue, E.-W., O’Connor, P., Polman, C., Hohlfeld, R., Calabresi, P., et al. (2010). A placebo-controlled trial of oral fingolimod in relapsing multiple sclerosis. N. Engl. J. Med. 362, 387-401. doi: 10.1056/NEJMoa0 909494

Karaca, I., Tamboli, I. Y., Glebov, K., Richter, J., Fell, L. H., Grimm, M. O., et al. (2014). Deficiency of Sphingosine-1-phosphate Lyase Impairs Lysosomal Metabolism of the Amyloid Precursor Protein. J. Biol. Chem. 289, 16761-16772. doi: 10.1074/jbc.M113.535500

Kataoka, H., Sugahara, K., Shimano, K., Teshima, K., Koyama, M., Fukunari, A., et al. (2005). FTY720, sphingosine 1-phosphate receptor modulator, ameliorates experimental autoimmune encephalomyelitis by inhibition of $\mathrm{T}$ cell infiltration. Cell. Mol. Immunol. 2, 439-448.

Katsel, P., Li, C., and Haroutunian, V. (2007). Gene expression alterations in the sphingolipid metabolism pathways during progression of dementia and Alzheimer's disease: a shift toward ceramide accumulation at the earliest recognizable stages of Alzheimer's disease? Neurochem. Res. 32, 845-856. doi: 10. 1007/s11064-007-9297-x

Kawahara, A., Nishi, T., Hisano, Y., Fukui, H., Yamaguchi, A., and Mochizuki, N. (2009). The sphingolipid transporter spns2 functions in migration of zebrafish myocardial precursors. Science 323, 524-527. doi: 10.1126/science. 1167449

Kebir, H., Kreymborg, K., Ifergan, I., Dodelet-Devillers, A., Cayrol, R., Bernard, M., et al. (2007). Human TH17 lymphocytes promote blood-brain barrier disruption and central nervous system inflammation. Nat. Med. 13, 1173-1175. doi: $10.1038 / \mathrm{nm} 1651$

Kim, H. J., Miron, V. E., Dukala, D., Proia, R. L., Ludwin, S. K., Traka, M., et al. (2011). Neurobiological effects of sphingosine 1-phosphate receptor modulation in the cuprizone model. FASEB J. 25, 1509-1518. doi: 10.1096/fj.10173203

Kipnis, J., Cohen, H., Cardon, M., Ziv, Y., and Schwartz, M. (2004). T cell deficiency leads to cognitive dysfunction: implications for therapeutic vaccination for schizophrenia and other psychiatric conditions. Proc. Natl. Acad. Sci. U S A 101, 8180-8185. doi: 10.1073/pnas.0402268101

Kiuchi, M., Adachi, K., Kohara, T., Minoguchi, M., Hanano, T., Aoki, Y., et al. (2000). Synthesis and immunosuppressive activity of 2-substituted 2aminopropane-1,3-diols and 2-aminoethanols. J. Med. Chem. 43, 2946-2961. doi: $10.1021 / \mathrm{jm} 000173 \mathrm{z}$

Kleinschnitz, C., Kraft, P., Dreykluft, A., Hagedorn, I., Göbel, K., Schuhmann, M. K., et al. (2013). Regulatory T cells are strong promoters of acute ischemic stroke in mice by inducing dysfunction of the cerebral microvasculature. Blood 121, 679-691. doi: 10.1182/blood-2012-04-426734

Kleinschnitz, C., Schwab, N., Kraft, P., Hagedorn, I., Dreykluft, A., Schwarz, T., et al. (2010). Early detrimental T-cell effects in experimental cerebral ischemia are neither related to adaptive immunity nor thrombus formation. Blood 115, 38353842. doi: 10.1182/blood-2009-10-249078
Kluk, M. J., and Hla, T. (2002). Signaling of sphingosine-1-phosphate via the S1P/EDG-family of G-protein-coupled receptors. Biochim. Biophys. Acta 1582, 72-80. doi: 10.1016/s1388-1981(02)00139-7

Kolbeck, R., Bartke, I., Eberle, W., and Barde, Y. A. (1999). Brain-derived neurotrophic factor levels in the nervous system of wild-type and neurotrophin gene mutant mice. J. Neurochem. 72, 1930-1938. doi: 10.1046/j.1471-4159.1999. 0721930.x

Kolesnick, R. N. (1991). Sphingomyelin and derivatives as cellular signals. Prog. Lipid Res. 30, 1-38. doi: 10.1016/0163-7827(91)90005-p

Kowarik, M. C., Pellkofer, H. L., Cepok, S., Korn, T., Kümpfel, T., Buck, D., et al. (2011). Differential effects of fingolimod (FTY720) on immune cells in the CSF and blood of patients with MS. Neurology 76, 1214-1221. doi: 10.1212/WNL. 0b013e3182143564

Kraft, P., Göb, E., Schuhmann, M. K., Göbel, K., Deppermann, C., Thielmann, I., et al. (2013). FTY720 ameliorates acute ischemic stroke in mice by reducing thrombo-inflammation but not by direct neuroprotection. Stroke 44, 32023210. doi: 10.1161/STROKEAHA.113.002880

Lahiri, S., Park, H., Laviad, E. L., Lu, X., Bittman, R., and Futerman, A. H. (2009). Ceramide synthesis is modulated by the sphingosine analog FTY720 via a mixture of uncompetitive and noncompetitive inhibition in an Acyl-CoA chain length-dependent manner. J. Biol. Chem. 284, 16090-16098. doi: 10.1074/jbc. M807438200

Latour, L. L., Kang, D.-W., Ezzeddine, M. A., Chalela, J. A., and Warach, S. (2004). Early blood-brain barrier disruption in human focal brain ischemia. Ann. Neurol. 56, 468-477. doi: 10.1002/ana.20199

Ledgerwood, L. G., Lal, G., Zhang, N., Garin, A., Esses, S. J., Ginhoux, F., et al. (2008). The sphingosine 1-phosphate receptor 1 causes tissue retention by inhibiting the entry of peripheral tissue $\mathrm{T}$ lymphocytes into afferent lymphatics. Nat. Immunol. 9, 42-53. doi: 10.1038/ni1534

Lees, K. R., Bluhmki, E., von Kummer, R., Brott, T. G., Toni, D., Grotta, J. C., et al. (2010). Time to treatment with intravenous alteplase and outcome in stroke: an updated pooled analysis of ECASS, ATLANTIS, NINDS and EPITHET trials. Lancet 375, 1695-1703. doi: 10.1016/S0140-6736(10)60491-6

Lepley, D., Paik, J.-H., Hla, T., and Ferrer, F. (2005). The G protein-coupled receptor $\mathrm{S} 1 \mathrm{P} 2$ regulates $\mathrm{Rho} / \mathrm{Rho}$ kinase pathway to inhibit tumor cell migration. Cancer Res. 65, 3788-3795. doi: 10.1158/0008-5472.can-04-2311

Le Stunff, H., Peterson, C., Liu, H., Milstien, S., and Spiegel, S. (2002). Sphingosine1-phosphate and lipid phosphohydrolases. Biochim. Biophys. Acta 1582, 8-17. doi: 10.1016/s1388-1981(02)00132-4

Liesz, A., Sun, L., Zhou, W., Schwarting, S., Mracsko, E., Zorn, M., et al. (2011). FTY720 reduces post-ischemic brain lymphocyte influx but does not improve outcome in permanent murine cerebral ischemia. PLoS One 6:e21312. doi: 10. 1371/journal.pone.0021312

Lim, K. G., Tonelli, F., Li, Z., Lu, X., Bittman, R., Pyne, S., et al. (2011). FTY720 analogues as sphingosine kinase 1 inhibitors: enzyme inhibition kinetics, allosterism, proteasomal degradation, and actin rearrangement in MCF7 breast cancer cells. J. Biol. Chem. 286, 18633-18640. doi: 10.1074/jbc.M111. 220756

Lloyd-Evans, E., Morgan, A. J., He, X., Smith, D. A., Elliot-Smith, E., Sillence, D. J., et al. (2008). Niemann-Pick disease type $\mathrm{Cl}$ is a sphingosine storage disease that causes deregulation of lysosomal calcium. Nat. Med. 14, 1247-1255. doi: 10. 1038/nm. 1876

Lock, C., Hermans, G., Pedotti, R., Brendolan, A., Schadt, E., Garren, H., et al. (2002). Gene-microarray analysis of multiple sclerosis lesions yields new targets validated in autoimmune encephalomyelitis. Nat. Med. 8, 500-508. doi: 10. 1038/nm0502-500

Lu, L., Barfejani, A. H., Qin, T., Dong, Q., Ayata, C., and Waeber, C. (2014). Fingolimod exerts neuroprotective effects in a mouse model of intracerebral hemorrhage. Brain Res. 1555, 89-96. doi: 10.1016/j.brainres.2014. 01.048

Lukasiuk, K., Dabrowski, M., Adach, A., and Pitkänen, A. (2006). Epileptogenesisrelated genes revisited. Prog. Brain Res. 158, 223-241. doi: 10.1016/s00796123(06)58011-2

Lukiw, W. J., and Bazan, N. G. (2006). Survival signalling in Alzheimer's disease. Biochem. Soc. Trans. 34, 1277-1282. doi: 10.1042/bst0341277

MacLennan, A. J., Carney, P. R., Zhu, W. J., Chaves, A. H., Garcia, J., Grimes, J. R., et al. (2001). An essential role for the H218/AGR16/Edg-5/LP(B2) sphingosine 1-phosphate receptor in neuronal excitability. Eur. J. Neurosci. 14, 203-209. doi: 10.1046/j.0953-816x.2001.01634.x 
Maggio, N., Itsekson, Z., Ikenberg, B., Strehl, A., Vlachos, A., Blatt, I., et al. (2014). The anticoagulant activated protein $\mathrm{C}(\mathrm{aPC})$ promotes metaplasticity in the hippocampus through an EPCR-PAR1-S1P1 receptors dependent mechanism. Hippocampus 24, 1030-1038. doi: 10.1002/hipo.22288

Maggio, N., Shavit, E., Chapman, J., and Segal, M. (2008). Thrombin induces longterm potentiation of reactivity to afferent stimulation and facilitates epileptic seizures in rat hippocampal slices: toward understanding the functional consequences of cerebrovascular insults. J. Neurosci. 28, 732-736. doi: 10. 1523/JNEUROSCI.3665-07.2008

Maglione, V., Marchi, P., Di Pardo, A., Lingrell, S., Horkey, M., Tidmarsh, E., et al. (2010). Impaired ganglioside metabolism in Huntington's disease and neuroprotective role of GM1. J. Neurosci. 30, 4072-4080. doi: 10.1523/JNEUROSCI. 6348-09.2010

Mandala, S., Hajdu, R., Bergstrom, J., Quackenbush, E., Xie, J., Milligan, J., et al. (2002). Alteration of lymphocyte trafficking by sphingosine-1phosphate receptor agonists. Science 296, 346-349. doi: 10.1126/science. 1070238

Mannaioni, G., Orr, A. G., Hamill, C. E., Yuan, H., Pedone, K. H., McCoy, K. L., et al. (2008). Plasmin potentiates synaptic N-methyl-D-aspartate receptor function in hippocampal neurons through activation of proteaseactivated receptor-1. J. Biol. Chem. 283, 20600-20611. doi: 10.1074/jbc.M8030 15200

Mansoor, M., and Melendez, A. J. (2008). Recent trials for FTY720 (fingolimod): a new generation of immunomodulators structurally similar to sphingosine. Rev. Recent Clin. Trials 3, 62-69. doi: 10.2174/1574887087833 30486

Maroso, M., Balosso, S., Ravizza, T., Iori, V., Wright, C. I., French, J., et al. (2011). Interleukin-1 $\beta$ biosynthesis inhibition reduces acute seizures and drug resistant chronic epileptic activity in mice. Neurotherapeutics 8, 304-315. doi: 10 . 1007/s13311-011-0039-z

Masopust, D., Vezys, V., Marzo, A. L., and Lefrançois, L. (2001). Preferential localization of effector memory cells in nonlymphoid tissue. Science 291, 24132417. doi: $10.1126 /$ science. 1058867

Matloubian, M., Lo, C. G., Cinamon, G., Lesneski, M. J., Xu, Y., Brinkmann, V., et al. (2004). Lymphocyte egress from thymus and peripheral lymphoid organs is dependent on S1P receptor 1. Nature 427, 355-360. doi: 10.1038/nature02284

Mehling, M., Brinkmann, V., Antel, J., Bar-Or, A., Goebels, N., Vedrine, C., et al. (2008). FTY720 therapy exerts differential effects on T cell subsets in multiple sclerosis. Neurology 71, 1261-1267. doi: 10.1212/01.wnl.0000327609. 57688.ea

Meisel, C., Schwab, J. M., Prass, K., Meisel, A., and Dirnagl, U. (2005). Central nervous system injury-induced immune deficiency syndrome. Nat. Rev. Neurosci. 6, 775-786. doi: 10.1038/nrn1765

Mencl, S., Hennig, N., Hopp, S., Schuhmann, M. K., Albert-Weissenberger, C., Sirén, A. L., et al. (2014). FTY720 does not protect from traumatic brain injury in mice despite reducing posttraumatic inflammation. J. Neuroimmunol. doi: 10. 1016/j.jneuroim.2014.07.010. [Epub ahead of print].

Mielke, M. M., Haughey, N. J., Bandaru, V. V. R., Zetterberg, H., Blennow, K., Andreasson, U., et al. (2014). Cerebrospinal fluid sphingolipids, $\beta$-amyloid and tau in adults at risk for Alzheimer's disease. Neurobiol. Aging doi: 10.1016/j. neurobiolaging.2014.05.019. [Epub ahead of print].

Miron, V. E., Hall, J. A., Kennedy, T. E., Soliven, B., and Antel, J. P. (2008). Cyclical and dose-dependent responses of adult human mature oligodendrocytes to fingolimod. Am. J. Pathol. 173, 1143-1152. doi: 10.2353/ajpath.2008. 080478

Miron, V. E., Ludwin, S. K., Darlington, P. J., Jarjour, A. A., Soliven, B., Kennedy, T. E., et al. (2010). Fingolimod (FTY720) enhances remyelination following demyelination of organotypic cerebellar slices. Am. J. Pathol. 176, 2682-2694. doi: 10.2353/ajpath.2010.091234

Noda, H., Takeuchi, H., Mizuno, T., and Suzumura, A. (2013). Fingolimod phosphate promotes the neuroprotective effects of microglia. J. Neuroimmunol. 256, 13-18. doi: 10.1016/j.jneuroim.2012.12.005

Ntranos, A., Hall, O., Robinson, D. P., Grishkan, I. V., Schott, J. T., Tosi, D. M., et al. (2014). FTY720 impairs CD8 T-cell function independently of the sphingosine1-phosphate pathway. J. Neuroimmunol. 270, 13-21. doi: 10.1016/j.jneuroim. 2014.03.007

Osenkowski, P., Ye, W., Wang, R., Wolfe, M. S., and Selkoe, D. J. (2008). Direct and potent regulation of gamma-secretase by its lipid microenvironment. J. Biol. Chem. 283, 22529-22540. doi: 10.1074/jbc.M801925200
Papadopoulos, D., Rundle, J., Patel, R., Marshall, I., Stretton, J., Eaton, R., et al. (2010). FTY720 ameliorates MOG-induced experimental autoimmune encephalomyelitis by suppressing both cellular and humoral immune responses. J. Neurosci. Res. 88, 346-359. doi: 10.1002/jnr.22196

Paugh, S. W., Cassidy, M. P., He, H., Milstien, S., Sim-Selley, L. J., Spiegel, S., et al. (2006). Sphingosine and its analog, the immunosuppressant 2-amino2-(2-[4-octylphenyl] ethyl)-1,3-propanediol, interact with the CB1 cannabinoid receptor. Mol. Pharmacol. 70, 41-50.

Payne, S. G., Oskeritzian, C. A., Griffiths, R., Subramanian, P., Barbour, S. E., Chalfant, C. E., et al. (2007). The immunosuppressant drug FTY720 inhibits cytosolic phospholipase A2 independently of sphingosine-1-phosphate receptors. Blood 109, 1077-1085. doi: 10.1182/blood-2006-03-011437

Peng, X., Hassoun, P. M., Sammani, S., McVerry, B. J., Burne, M. J., Rabb, H., et al. (2004). Protective effects of sphingosine 1-phosphate in murine endotoxininduced inflammatory lung injury. Am. J. Respir. Crit. Care Med. 169, 12451251. doi: 10.1164/rccm.200309-1258oc

Pfeilschifter, W., Czech-Zechmeister, B., Sujak, M., Foerch, C., Wichelhaus, T. A. and Pfeilschifter, J. (2011a). Treatment with the immunomodulator FTY720 does not promote spontaneous bacterial infections after experimental stroke in mice. Exp. Transl. Stroke Med. 3:2. doi: 10.1186/2040-7378-3-2

Pfeilschifter, W., Czech-Zechmeister, B., Sujak, M., Mirceska, A., Koch, A., Rami, A., et al. (2011b). Activation of sphingosine kinase 2 is an endogenous protective mechanism in cerebral ischemia. Biochem. Biophys. Res. Commun. 413, 212-217. doi: 10.1016/j.bbrc.2011.08.070

Pham, T. H. M., Okada, T., Matloubian, M., Lo, C. G., and Cyster, J. G. (2008). S1P1 receptor signaling overrides retention mediated by $\mathrm{G}$ alpha i-coupled receptors to promote T cell egress. Immunity 28, 122-133. doi: 10.1016/j.immuni.2007. 11.017

Pitman, M. R., Woodcock, J. M., Lopez, A. F., and Pitson, S. M. (2012). Molecular targets of FTY720 (fingolimod). Curr. Mol. Med. 12, 1207-1219. doi: 10. 2174/156652412803833599

Puglielli, L., Ellis, B. C., Saunders, A. J., and Kovacs, D. M. (2003). Ceramide stabilizes beta-site amyloid precursor protein-cleaving enzyme 1 and promotes amyloid beta-peptide biogenesis. J. Biol. Chem. 278, 19777-19783. doi: 10. 1074/jbc.m300466200

Qin, J., Berdyshev, E., Goya, J., Natarajan, V., and Dawson, G. (2010). Neurons and oligodendrocytes recycle sphingosine 1-phosphate to ceramide: significance for apoptosis and multiple sclerosis. J. Biol. Chem. 285, 14134-14143. doi: 10. 1074/jbc.M109.076810

Rao, R. S., Medhi, B., Saikia, U. N., Arora, S. K., Toor, J. S., Khanduja, K. L., et al. (2008). Experimentally induced various inflammatory models and seizure: understanding the role of cytokine in rat. Eur. Neuropsychopharmacol. 18, 760767. doi: 10.1016/j.euroneuro.2008.06.008

Rauskolb, S., Zagrebelsky, M., Dreznjak, A., Deogracias, R., Matsumoto, T., Wiese, S., et al. (2010). Global deprivation of brain-derived neurotrophic factor in the CNS reveals an area-specific requirement for dendritic growth. J. Neurosci. 30, 1739-1749. doi: 10.1523/JNEUROSCI.5100-09.2010

Ravizza, T., Balosso, S., and Vezzani, A. (2011). Inflammation and prevention of epileptogenesis. Neurosci. Lett. 497, 223-230. doi: 10.1016/j.neulet.2011. 02.040

Rolland, W. B., Lekic, T., Krafft, P. R., Hasegawa, Y., Altay, O., Hartman, R., et al. (2013). Fingolimod reduces cerebral lymphocyte infiltration in experimental models of rodent intracerebral hemorrhage. Exp. Neurol. 241, 45-55. doi: 10. 1016/j.expneurol.2012.12.009

Rolland, W. B., Manaenko, A., Lekic, T., Hasegawa, Y., Ostrowski, R., Tang, J., et al. (2011). FTY720 is neuroprotective and improves functional outcomes after intracerebral hemorrhage in mice. Acta Neurochir. Suppl. 111, 213-217. doi: 10. 1007/978-3-7091-0693-8_36

Rossi, S., Lo Giudice, T., De Chiara, V., Musella, A., Studer, V., Motta, C., et al. (2012). Oral fingolimod rescues the functional deficits of synapses in experimental autoimmune encephalomyelitis. Br. J. Pharmacol. 165, 861-869. doi: 10. 1111/j.1476-5381.2011.01579.x

Ruvolo, P. (2003). Intracellular signal transduction pathways activated by ceramide and its metabolites. Pharmacol. Res. 47, 383-392. doi: 10.1016/s10436618(03)00050-1

Salomon, D. S., Brandt, R., Ciardiello, F., and Normanno, N. (1995). Epidermal growth factor-related peptides and their receptors in human malignancies. Crit. Rev. Oncol. Hematol. 19, 183-232. doi: 10.1016/1040-8428(94) 00144-i 
Sandhoff, K., and Christomanou, H. (1979). Biochemistry and genetics of gangliosidoses. Hum. Genet. 50, 107-143. doi: 10.1007/bf00390234

Schiffmann, S., Ferreiros, N., Birod, K., Eberle, M., Schreiber, Y., Pfeilschifter, W., et al. (2012). Ceramide synthase 6 plays a critical role in the development of experimental autoimmune encephalomyelitis. J. Immunol. 188, 5723-5733. doi: 10.4049/jimmunol.1103109

Schmid, D. A., Yang, T., Ogier, M., Adams, I., Mirakhur, Y., Wang, Q., et al. (2012). A TrkB small molecule partial agonist rescues TrkB phosphorylation deficits and improves respiratory function in a mouse model of Rett syndrome. J. Neurosci. 32, 1803-1810. doi: 10.1523/JNEUROSCI.0865-11.2012

Schwalm, S., Döll, F., Römer, I., Bubnova, S., Pfeilschifter, J., and Huwiler, A. (2008). Sphingosine kinase-1 is a hypoxia-regulated gene that stimulates migration of human endothelial cells. Biochem. Biophys. Res. Commun. 368, 10201025. doi: 10.1016/j.bbrc.2008.01.132

Sharkey, J., Crawford, J. H., Butcher, S. P., and Marston, H. M. (1996). Tacrolimus (FK506) ameliorates skilled motor deficits produced by middle cerebral artery occlusion in rats. Stroke 27, 2282-2286. doi: 10.1161/01.str.27. 12.2282

Shichita, T., Sugiyama, Y., Ooboshi, H., Sugimori, H., Nakagawa, R., Takada, I., et al. (2009). Pivotal role of cerebral interleukin-17-producing gammadeltaT cells in the delayed phase of ischemic brain injury. Nat. Med. 15, 946-950. doi: 10. 1038/nm.1999

Skon, C. N., Lee, J.-Y., Anderson, K. G., Masopust, D., Hogquist, K. A., and Jameson, S. C. (2013). Transcriptional downregulation of S1prl is required for the establishment of resident memory CD8+ T cells. Nat. Immunol. 14, 12851293. doi: $10.1038 /$ ni.2745

Sonoda, Y., Yamamoto, D., Sakurai, S., Hasegawa, M., Aizu-Yokota, E., Momoi, T., et al. (2001). FTY720, a novel immunosuppressive agent, induces apoptosis in human glioma cells. Biochem. Biophys. Res. Commun. 281, 282-288. doi: 10. 1006/bbrc.2001.4352

Sugita, K., Kabashima, K., Sakabe, J.-I., Yoshiki, R., Tanizaki, H., and Tokura, Y. (2010). FTY720 regulates bone marrow egress of eosinophils and modulates late-phase skin reaction in mice. Am. J. Pathol. 177, 1881-1887. doi: 10 2353/ajpath.2010.100119

Sun, Y., Li, Q.-F., Zhang, Y., Hu, R., and Jiang, H. (2013). Isoflurane preconditioning increases survival of rat skin random-pattern flaps by induction of HIF-1 $\alpha$ expression. Cell. Physiol. Biochem. 31, 579-591. doi: 10.1159/000 350078

Takasugi, N., Sasaki, T., Ebinuma, I., Osawa, S., Isshiki, H., Takeo, K., et al. (2013). FTY720/fingolimod, a sphingosine analogue, reduces amyloid$\beta$ production in neurons. PLoS One 8:e64050. doi: 10.1371/journal.pone. 0064050

Takasugi, N., Sasaki, T., Suzuki, K., Osawa, S., Isshiki, H., Hori, Y., et al. (2011). BACE1 activity is modulated by cell-associated sphingosine-1-phosphate. J. Neurosci. 31, 6850-6857. doi: 10.1523/JNEUROSCI.6467-10.2011

Tamboli, I. Y., Prager, K., Barth, E., Heneka, M., Sandhoff, K., and Walter, J. (2005). Inhibition of glycosphingolipid biosynthesis reduces secretion of the beta-amyloid precursor protein and amyloid beta-peptide. J. Biol. Chem. 280, 28110-28117. doi: $10.1074 /$ jbc.m414525200

Thangada, S., Khanna, K. M., Blaho, V. A., Oo, M. L., Im, D.-S., Guo, C., et al. (2010). Cell-surface residence of sphingosine 1-phosphate receptor 1 on lymphocytes determines lymphocyte egress kinetics. J. Exp. Med. 207, 14751483. doi: $10.1084 /$ jem. 20091343

Thijs, V. N., Adami, A., Neumann-Haefelin, T., Moseley, M. E., and Albers, G. W. (2002). Clinical and radiological correlates of reduced cerebral blood flow measured using magnetic resonance imaging. Arch. Neurol. 59, 233-238. doi: 10. 1001/archneur.59.2.233

Tsai, C.-F., Thomas, B., and Sudlow, C. L. M. (2013). Epidemiology of stroke and its subtypes in Chinese vs. white populations: a systematic review. Neurology 81, 264-272. doi: 10.1212/WNL.0b013e31829bfde3

Tzartos, J. S., Friese, M. A., Craner, M. J., Palace, J., Newcombe, J., Esiri, M. M., et al. (2008). Interleukin-17 production in central nervous system-infiltrating $\mathrm{T}$ cells and glial cells is associated with active disease in multiple sclerosis. Am. J. Pathol. 172, 146-155. doi: 10.2353/ajpath.2008.070690

Van Brocklyn, J. R., Jackson, C. A., Pearl, D. K., Kotur, M. S., Snyder, P. J., and Prior, T. W. (2005). Sphingosine kinase-1 expression correlates with poor survival of patients with glioblastoma multiforme: roles of sphingosine kinase isoforms in growth of glioblastoma cell lines. J. Neuropathol. Exp. Neurol. 64, 695-705. doi: 10.1097/01.jnen.0000175329.59092.2c
Van Brocklyn, J., Letterle, C., Snyder, P., and Prior, T. (2002). Sphingosine1-phosphate stimulates human glioma cell proliferation through Gi-coupled receptors: role of ERK MAP kinase and phosphatidylinositol 3-kinase beta. Cancer Lett. 181, 195-204. doi: 10.1016/s0304-3835(02)00050-2

Van Brocklyn, J. R., Young, N., and Roof, R. (2003). Sphingosine-1-phosphate stimulates motility and invasiveness of human glioblastoma multiforme cells. Cancer Lett. 199, 53-60. doi: 10.1016/s0304-3835(03)00334-3

van Doorn, R., Nijland, P. G., Dekker, N., Witte, M. E., Lopes-Pinheiro, M. A., van het Hof, B., et al. (2012). Fingolimod attenuates ceramide-induced blood-brain barrier dysfunction in multiple sclerosis by targeting reactive astrocytes. Acta Neuropathol. 12, 397-410. doi: 10.1007/s00401-012-1014-4

Verderio, C., Muzio, L., Turola, E., Bergami, A., Novellino, L., Ruffini, F., et al. (2012). Myeloid microvesicles are a marker and therapeutic target for neuroinflammation. Ann. Neurol. 72, 610-624. doi: 10.1002/ana.23627

Vezzani, A., and Friedman, A. (2011). Brain inflammation as a biomarker in epilepsy. Biomark. Med. 5, 607-614. doi: 10.2217/bmm.11.61

Wacker, B. K., Park, T. S., and Gidday, J. M. (2009). Hypoxic preconditioninginduced cerebral ischemic tolerance: role of microvascular sphingosine kinase 2. Stroke 40, 3342-3348. doi: 10.1161/STROKEAHA.109.560714

Wacker, B. K., Perfater, J. L., and Gidday, J. M. (2012). Hypoxic preconditioning induces stroke tolerance in mice via a cascading HIF, sphingosine kinase and CCL2 signaling pathway. J. Neurochem. 123, 954-962. doi: 10.1111/jnc. 12047

Walzer, T., Chiossone, L., Chaix, J., Calver, A., Carozzo, C., Garrigue-Antar, L., et al. (2007). Natural killer cell trafficking in vivo requires a dedicated sphingosine 1phosphate receptor. Nat. Immunol. 8, 1337-1344. doi: 10.1038/ni1523

Webb, M., Tham, C.-S., Lin, F.-F., Lariosa-Willingham, K., Yu, N., Hale, J., et al. (2004). Sphingosine 1-phosphate receptor agonists attenuate relapsingremitting experimental autoimmune encephalitis in SJL mice. J. Neuroimmunol. 153, 108-121. doi: 10.1016/j.jneuroim.2004.04.015

Wei, Y., Yemisci, M., Kim, H.-H., Yung, L. M., Shin, H. K., Hwang, S.-K., et al. (2011). Fingolimod provides long-term protection in rodent models of cerebral ischemia. Ann. Neurol. 69, 119-129. doi: 10.1002/ana.22186

Wilson, E., Olcott, M. C., Bell, R. M., Merrill, A. H., and Lambeth, J. D. (1986). Inhibition of the oxidative burst in human neutrophils by sphingoid long-chain bases. Role of protein kinase C in activation of the burst. J. Biol. Chem. 261, 12616-12623.

Wu, C., Leong, S. Y., Moore, C. S., Cui, Q. L., Gris, P., Bernier, L.-P., et al. (2013). Dual effects of daily FTY720 on human astrocytes in vitro: relevance for neuroinflammation. J. Neuroinflammation 10:41. doi: 10.1186/17422094-10-41

Xie, D., Yin, D., Tong, X., O’Kelly, J., Mori, A., Miller, C., et al. (2004a). Cyr61 is overexpressed in gliomas and involved in integrin-linked kinase-mediated Akt and beta-catenin-TCF/Lef signaling pathways. Cancer Res. 64, 1987-1996. doi: 10.1158/0008-5472.can-03-0666

Xie, D., Yin, D., Wang, H.-J., Liu, G.-T., Elashoff, R., Black, K., et al. (2004b). Levels of expression of CYR61 and CTGF are prognostic for tumor progression and survival of individuals with gliomas. Clin. Cancer Res. 10, 2072-2081. doi: 10. 1158/1078-0432.ccr-0659-03

Xiong, Y., and Hla, T. (2014). S1P control of endothelial integrity. Curr. Top. Microbiol. Immunol. 378, 85-105. doi: 10.1007/978-3-319-05879-5_4

Yanagawa, Y., Sugahara, K., Kataoka, H., Kawaguchi, T., Masubuchi, Y., and Chiba, K. (1998). FTY720, a novel immunosuppressant, induces sequestration of circulating mature lymphocytes by acceleration of lymphocyte homing in rats. II. FTY720 prolongs skin allograft survival by decreasing T cell infiltration into grafts but not cytokine production in vivo. J. Immunol. 160, 5493-5499.

Young, N., Pearl, D. K., and Van Brocklyn, J. R. (2009). Sphingosine-1-phosphate regulates glioblastoma cell invasiveness through the urokinase plasminogen activator system and CCN1/Cyr61. Mol. Cancer Res. 7, 23-32. doi: 10.1158/ 1541-7786.mcr-08-0061

Young, N., and Van Brocklyn, J. R. (2009). Roles of sphingosine-1-phosphate (S1P) receptors in malignant behavior of glioma cells. Differential effects of S1P2 on cell migration and invasiveness. Exp. Cell Res. 313, 1615-1627. doi: 10.1016/j. yexcr.2007.02.009

Yuan, H., Vance, K. M., Junge, C. E., Geballe, M. T., Snyder, J. P., Hepler, J. R., et al. (2009). The serine protease plasmin cleaves the amino-terminal domain of the NR2A subunit to relieve zinc inhibition of the $\mathrm{N}$-methyl-D-aspartate receptors. J. Biol. Chem. 284, 12862-12873. doi: 10.1074/jbc.m805123200 
Yung, L. M., Wei, Y., Qin, T., Wang, Y., Smith, C. D., and Waeber, C. (2012). Sphingosine kinase 2 mediates cerebral preconditioning and protects the mouse brain against ischemic injury. Stroke 43, 199-204. doi: 10.1161/strokeaha.111. 626911

Zhang, M., Martin, B. R., Adler, M. W., Razdan, R. J., Kong, W., Ganea, D., et al. (2009). Modulation of cannabinoid receptor activation as a neuroprotective strategy for EAE and stroke. J. Neuroimmune Pharmacol. 4, 249-259. doi: 10. 1007/s11481-009-9148-4

Zhang, L., Wang, H.-D., Ji, X.-J., Cong, Z.-X., Zhu, J.-H., and Zhou, Y. (2013). FTY720 for cancer therapy (Review). Oncol. Rep. 30, 2571-2578. doi: 10.3892/or. 2013.2765

Zheng, H., and Koo, E. H. (2011). Biology and pathophysiology of the amyloid precursor protein. Mol. Neurodegener. 6:27. doi: 10.1186/1750-1326-6-27

Zuccato, C., Ciammola, A., Rigamonti, D., Leavitt, B. R., Goffredo, D., Conti, L., et al. (2001). Loss of huntingtin-mediated BDNF gene transcription in Huntington's disease. Science 293, 493-498. doi: 10.1126/science.1059581
Conflict of Interest Statement: The authors declare that the research was conducted in the absence of any commercial or financial relationships that could be construed as a potential conflict of interest.

Received: 08 August 2014; paper pending published: 15 August 2014; accepted: 25 August 2014; published online: 12 September 2014.

Citation: Brunkhorst R, Vutukuri R and Pfeilschifter W (2014) Fingolimod for the treatment of neurological diseases-state of play and future perspectives. Front. Cell. Neurosci. 8:283. doi: 10.3389/fncel.2014.00283

This article was submitted to the journal Frontiers in Cellular Neuroscience.

Copyright $\odot 2014$ Brunkhorst, Vutukuri and Pfeilschifter. This is an open-access article distributed under the terms of the Creative Commons Attribution License (CC BY). The use, distribution or reproduction in other forums is permitted, provided the original author(s) or licensor are credited and that the original publication in this journal is cited, in accordance with accepted academic practice. No use, distribution or reproduction is permitted which does not comply with these terms. 